KCP.613-5302

Distribution Category UC-706

Approved for public release; distribution is unlimited.

\title{
VISION-SENSING IMAGE ANALYSIS FOR GTAW PROCESS CONTROL
}

D. D. Long

Published November 1994

Topical Report

G. J. Daumeyer III, Project Leader

Project Team:

D. D. Long

D. L. Hollar, Jr.

A. W. Robbins 



\section{DISCLAIMER}

This report was prepared as an account of work sponsored by an agency of the United States Government. Neither the United States Government nor any agency thereof, nor any of their employees, make any warranty, express or implied, or assumes any legal liability or responsibility for the accuracy, completeness, or usefulness of any information, apparatus, product, or process disclosed, or represents that its use would not infringe privately owned rights. Reference herein to any specific commercial product, process, or service by trade name, trademark, manufacturer, or otherwise does not necessarily constitute or imply its endorsement, recommendation, or favoring by the United States Government or any agency thereof. The views and opinions of authors expressed herein do not necessarily state or reflect those of the United States Government or any agency thereof. 


\section{DISCLAIMER}

Portions of this document may be illegible in electronic image products. Images are produced from the best available original document. 


\section{Contents}

Section Page

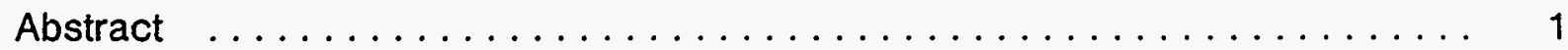

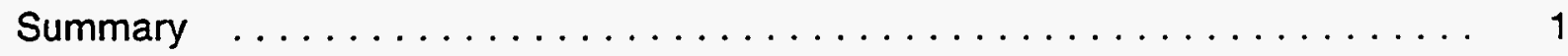

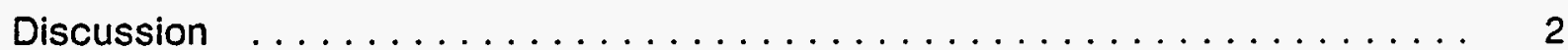

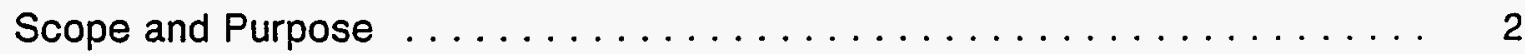

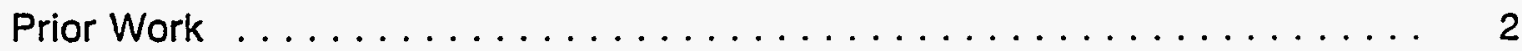

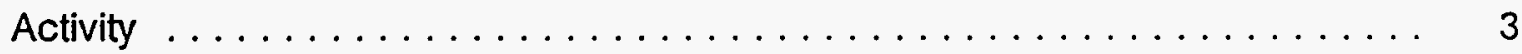

Vision-Sensing GTAW Electrode Holder $\ldots \ldots \ldots \ldots \ldots \ldots$

Equipment Setup $\quad \ldots \ldots \ldots \ldots \ldots \ldots \ldots \ldots \ldots \ldots \ldots \ldots \ldots \ldots \ldots$

Image Processing $\ldots \ldots \ldots \ldots \ldots \ldots \ldots \ldots \ldots$

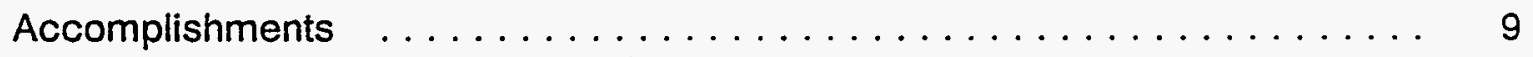

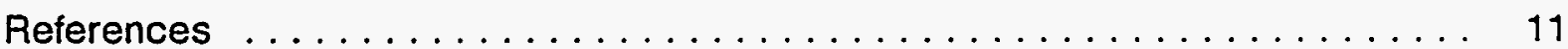

Appendices

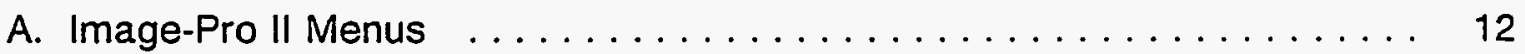

B. Examples of Vision Processing Operations Performed on Coaxially Viewed Images . . . . . . . . . . . . . . . . . 37

C. Pixel Intensity Data $\ldots \ldots \ldots \ldots \ldots \ldots \ldots \ldots \ldots \ldots \ldots \ldots$ 


\section{Illustrations}

Figure $\quad$ Page

1 GTAW Electrode Holder $\ldots \ldots \ldots \ldots \ldots \ldots \ldots \ldots \ldots \ldots \ldots$

2 Edge Flange Weld Joint Cross Section $\ldots \ldots \ldots \ldots \ldots \ldots$

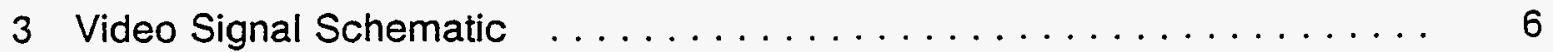

4 Coaxial View of GTAW Electrode Holder $\ldots \ldots \ldots \ldots \ldots \ldots$

5 Image of Weld Coupon $\ldots \ldots \ldots \ldots \ldots \ldots \ldots \ldots \ldots$

6 Line Profile Across the Weld Joint Above the Electrode Spot $\ldots \ldots \ldots$

7 Graph of Line Profile Data Contained in Appendix C . . . . . . . . . 10 


\section{Abstract}

Image analysis of a gas tungsten arc welding (GTAW) process was completed using video images from a charge coupled device (CCD) camera inside a specially designed coaxial (GTAW) electrode holder. Video data was obtained from filtered and unfiltered images, with and without the GTAW arc present, showing weld joint features and locations. Data Translation image processing boards, installed in an IBM PC AT 386 compatible computer, and Media Cybernetics image processing software were used to investigate edge flange weld joint geometry for image analysis.

\section{Summary}

Video analysis of images obtained from a charge coupled device (CCD) camera, coaxially aligned, inside a gas tungsten arc welding (GTAW) electrode holder has been accomplished using an IBM PC AT compatible computer containing Data Translation image processing boards and Media Cybernetics image processing software. Measurement of weld joint geometry features such as weld flange thickness and weld joint gap is possible using previously collected and analyzed data. Because it is possible to determine the weld joint geometry, verification of flange thickness and gap can be made during the welding process. In addition, a process control loop can be implemented to change the welding current based on the video analysis of a GTAW weld joint.

Achieving this milestone activity of analyzing video images was required for two reasons. First, successfully capturing, storing, filtering, processing, and analyzing an image from the coaxial GTAW electrode holder demonstrates that the torch was properly conceived and can be used in production. Second, by completing this milestone, additional work can be initiated to design and develop a coaxial GTAW video analysis process control loop. The image processing work completed to date demonstrates a high probability of success for using a process control loop based on a coaxial view of the GTAW process.

This report describes the image processing work completed to date and some fundamental concepts of video image analysis. Most importantly, this report describes how image analysis can be used to complete a process control loop with GTA welding. Specifically described is an approach that uses video information from a coaxial camera within a GTAW torch to determine flange thickness and then uses the flange thickness measurement to control the weld current. 


\section{Discussion}

\section{Scope and Purpose}

The scope of this investigation included the computer analysis of several video images from a charge coupled device (CCD) camera in a specially designed gas tungsten arc welding (GTAW) electrode holder. The images analyzed were altered or filtered at the camera as well as by the image processing boards in the computer. The image enhancements at the camera included polarizer filter adjustments and iris filter adjustments. The image processing operations performed by the image processing boards included convolution, Laplacian, Sobel, Roberts, and erosion techniques. The image processing was not done in real time due to the limitations of the hardware and software used in the investigation.

The purpose of this investigation was to prove that a CCD camera inside a specially designed GTAW electrode holder would provide a usable video image during welding for process control. This report describes, in general, the vision processing activities completed on images from the coaxial view of the GTAW electrode holder. Also described is the fact that these images do indeed provide control features data. The results indicate that the flange thickness and gap location can be measured.

\section{Prior Work}

The objective of this investigation is improved process control of the gas tungsten arc welding (GTAW) process. The primary method for improving process control is to utilize a specially designed GTAW electrode holder which has visionsensing capability. The vision-sensing GTAW electrode holder is designed with a charge coupled device (CCD) video camera aligned coaxially with the tungsten electrode. This coaxial view of the welding process provides a unique approach to process control by using video image analysis.

Weld joint image analysis is basically the determination of weld flange thickness, weld joint gap size, and weld joint location using electronic methods. In the CCD camera there is an array of $574 \times 489$ pixels which are illuminated with different intensities to form an image. The values and location of this pixel matrix are used for image analysis. Video image processing cards in a computer digitize the pixel matrix from an analog video signal. The pixel intensities are then used to determine features of the image. For welding process control, the flange thickness needs to be determined so that the correct welding current can be used to maintain constant penetration.

Image analysis on a computer provides digital calculations at a high enough rate that welding control can be provided during the welding process. Three fundamental pieces of information are required for basic control of the welding process: 1) weld flange thickness, 2) weld joint gap size, and 3 ) weld joint centerline location. This fundamental information has been extracted from images obtained by the 
coaxially aligned CCD camera inside the GTAW electrode holder.

\section{Activity}

\section{Vision-Sensing GTAW Electrode Holder}

A photograph of the GTAW electrode holder is shown in Figure 1. Inside the electrode holder is a video camera which operates on the RS-170 video standard. In front of the camera is a lens system which is remotely controlled. Focal length from 5 inches to 8 inches can be controlled. A controllable iris and a controllable polarizing filter are also housed inside the lens holder. This camera system provides the video signal to the vision-sensing computer. The video signal is also displayed on a monitor and can be recorded permanently on a video cassette recorder (VCR).

The design of this welding electrode holder provides a $360^{\circ}$ view of the welding area around the electrode. The video signal is recognizable whether the welding arc is present or not. The view of the welding area is a top view of the pieceparts being welded and is limited to a 0.75 -inch diameter around the electrode. The video signal captured by the camera system is sent to special image processing computer boards for analysis.

The view of AlliedSignal Inc., Kansas City Division's (KCD's), weld joints for vision processing is very different from the view of most coaxially processed welding images. Most industrial concerns process video images for butt welds or V-groove welds. A feedback control loop was completed by Richardson on a butt weld using a coaxial view GTAW electrode holder. 1 Richardson also developed techniques for looking ahead and behind the electrode of the GTAW process.2 Typically, KCD uses edge flange weld joint geometry on stainless steel housings which contain electronic assemblies. Clearly, the GTAW process must be well controlled to reduce heat input into the assembly and thus to reduce thermal stress on internal electronic components. The edge flange weld looks very different from a butt joint to a vision processing system. Understanding the image being processed is fundamental prior knowledge which must be understood when performing image processing and programming vision computers.

A cross section of the edge flange weld joint geometry is shown in Figure 2. To an image processor, the cross section of an edge flange weld joint looks quite different from a butt weld joint. $K C D$ is the only known industrial concern doing image processing of a coaxial view on an edge flange weld. As KCD's first step toward video image processing, the detection of the flange's outside and inside features is required. After detecting these features, the flange thickness can be measured. The combined flange thickness of $T_{1}$ and $\mathrm{T}_{2}$ is desired in order to control the welding current. $T_{1}$ and $T_{2}$ can be measured prior to welding with no arc light present or during the welding process with arc light present.

\section{Equipment Setup}

The vision processing for this investigation was accomplished using image processing boards from Data Translation. The image processing required two boards, a DT2861 frame grabber and a DT2858 frame processor. The frame grabber is designed to capture a video frame. Video frames are completely refreshed at the standard 


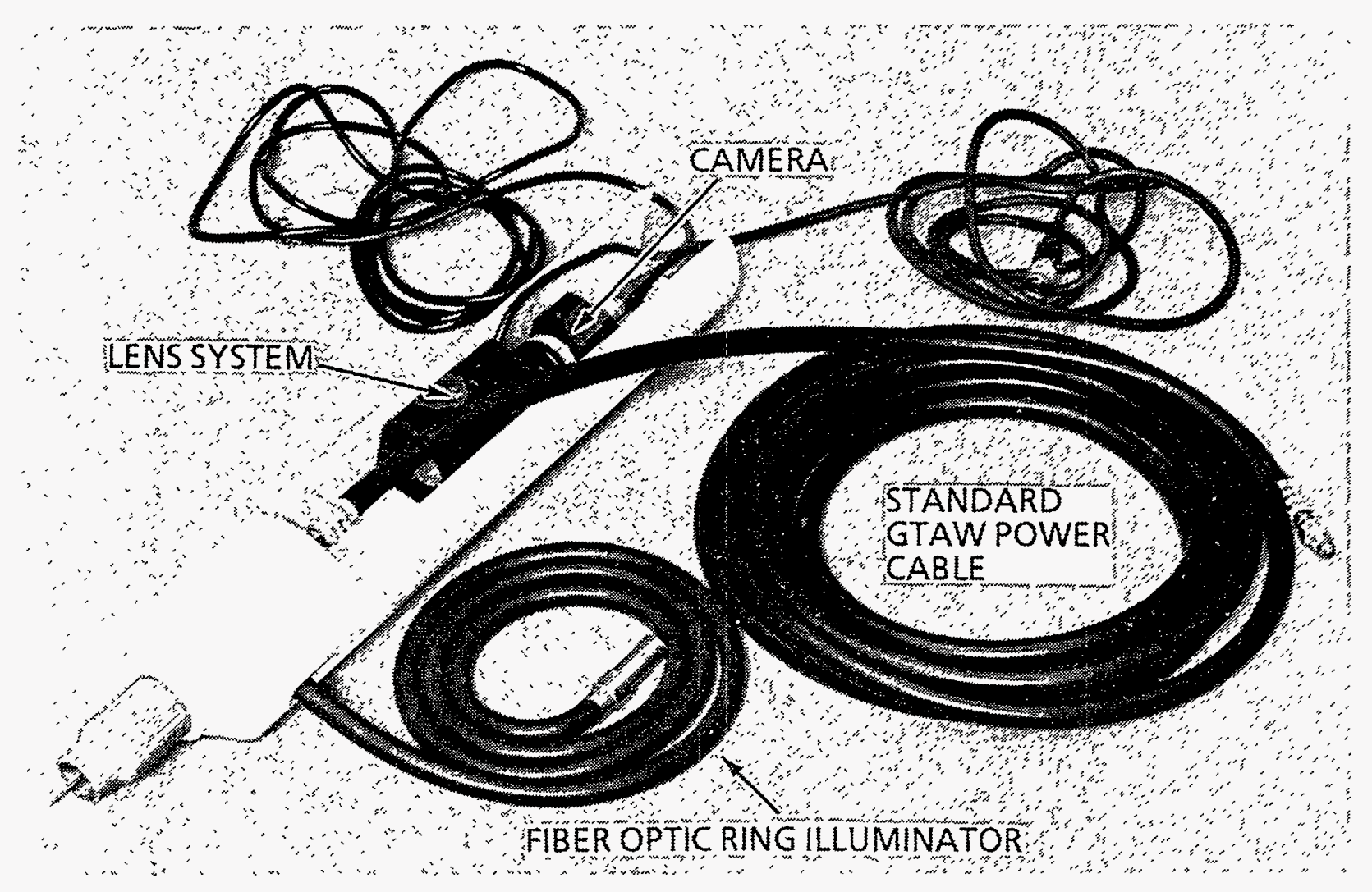

Figure 1. GTAW Electrode Holder

video rate of $30 \mathrm{~Hz}$. The image analysis of the coaxial GTAW video was not processed in real time due to the limitations of the existing hardware and software. However, from this investigation it was determined that 33-millisecond (real time) processing could be performed accurately with the proper video processing hardware and software. Figure 3 shows a block diagram of the equipment used in this investigation.

The software used for completing the vision analysis is from two vendors: Data Translation and Media Cybernetics. Complete computer screen prints of Media Cybernetics' Image Pro II software menus and available options are shown in Appendix A. Data Translation's Iris Tutor software does not provide menus to the user. Iris Tutor commands must be entered on the Iris Tutor command line to perform image processing operations. The Media Cybernetics Image Pro II software was used for the majority of this investigation.

\section{Image Processing}

Figure 4 shows a video frame from the coaxial view GTAW electrode holder. This figure is a photograph of the video monitor used for displaying processed and unprocessed video images. The dark spot in the center of the figure is the tungsten electrode. To the right of the figure is a smaller black spot which is on the coupon and is a flange thickness measurement marker. The three vertical black lines in the center of the figure and intersecting the 


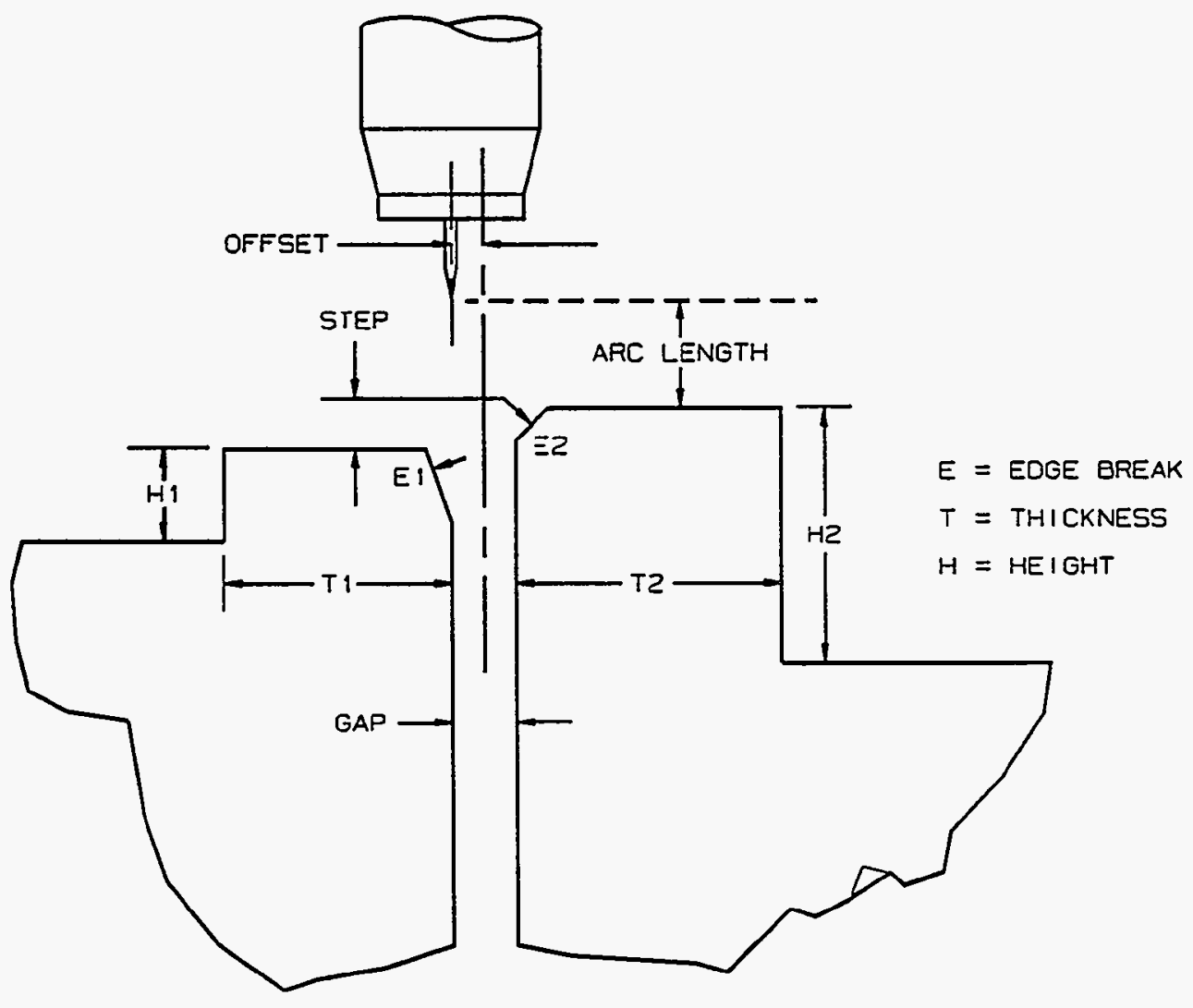

NOTE: THE DIRECTION CF WELDING TRAVEL IS INTO THE PAGE

Figure 2. Edge Flange Weld Joint Cross Section

center black spot are the outsides and middle of the edge flange weld joint geometry. The flanges machined into the coupons are of varying thickness with the thicker portion of the flange at the top of the figure. There is no arc light present because this image was captured from a non-welding condition. The flange thickness, $T_{1}+T_{2}$, just above the electrode spot is approximately 0.05 inch thick. The circle around the image is the 0.75 -inch inside diameter of the ceramic gas cup. This image has had no filtering or post processing such as convolution, Laplacian, Sobel, Roberts, or erosion techniques. The image was not filtered prior to capture by adjusting the lens system's iris or polarizer. The focal point of the image was half way down the flange height, $([\mathrm{H} 1 / 2]+[\mathrm{H} 2 / 2]) / 2$ from Figure 2.

An image from the same type of weld coupon is shown in Figure 5. The differences between Figure 4 and Figure 5 are as follows:

1. The welding arc is present. (Weld current is approximately 40 amperes.)

2. The flange thickness markers on the right of the image are offset.

3. The weld flange in the bottom half of the figure has been welded. 


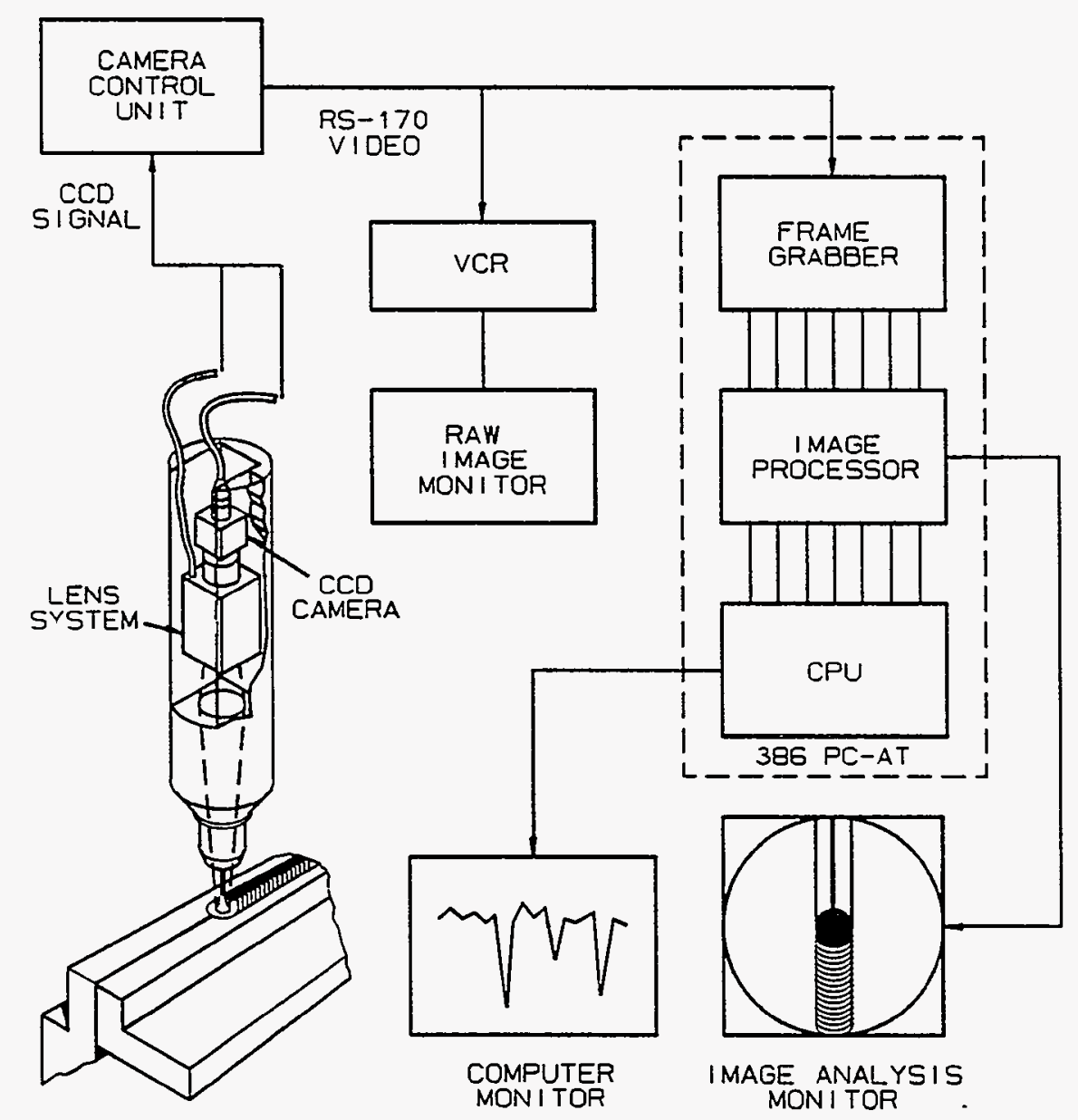

Figure 3. Video Signal Schematic

4. There is an area-of-interest box placed in the figure by the image processing software.

The area-of-interest region shows on the image where the vision processing of critical parameters is made. The flange thickness and gap size are determined from this portion of the image. Once the vision-sensing computer system determines the flange thickness and gap size, a calculation is made to determine the welding current required to maintain a constant penetration while minimizing temperature rise. After executing the algorithm for the required welding current, the vision-sensing computer can then issue a control signal to the GTA welding power supply to adjust the welding current as required.

Both Figure 4 and Figure 5 are considered raw images because there was no filtering or preprocessing of the image. Filtering or preprocessing of the image can be done at the video camera or on the image processing boards. Filtering or preprocessing is done to enhance the image and reduce or eliminate noise signals. Several examples of the preprocessing or signal conditioning are given in Appendix $B$. 


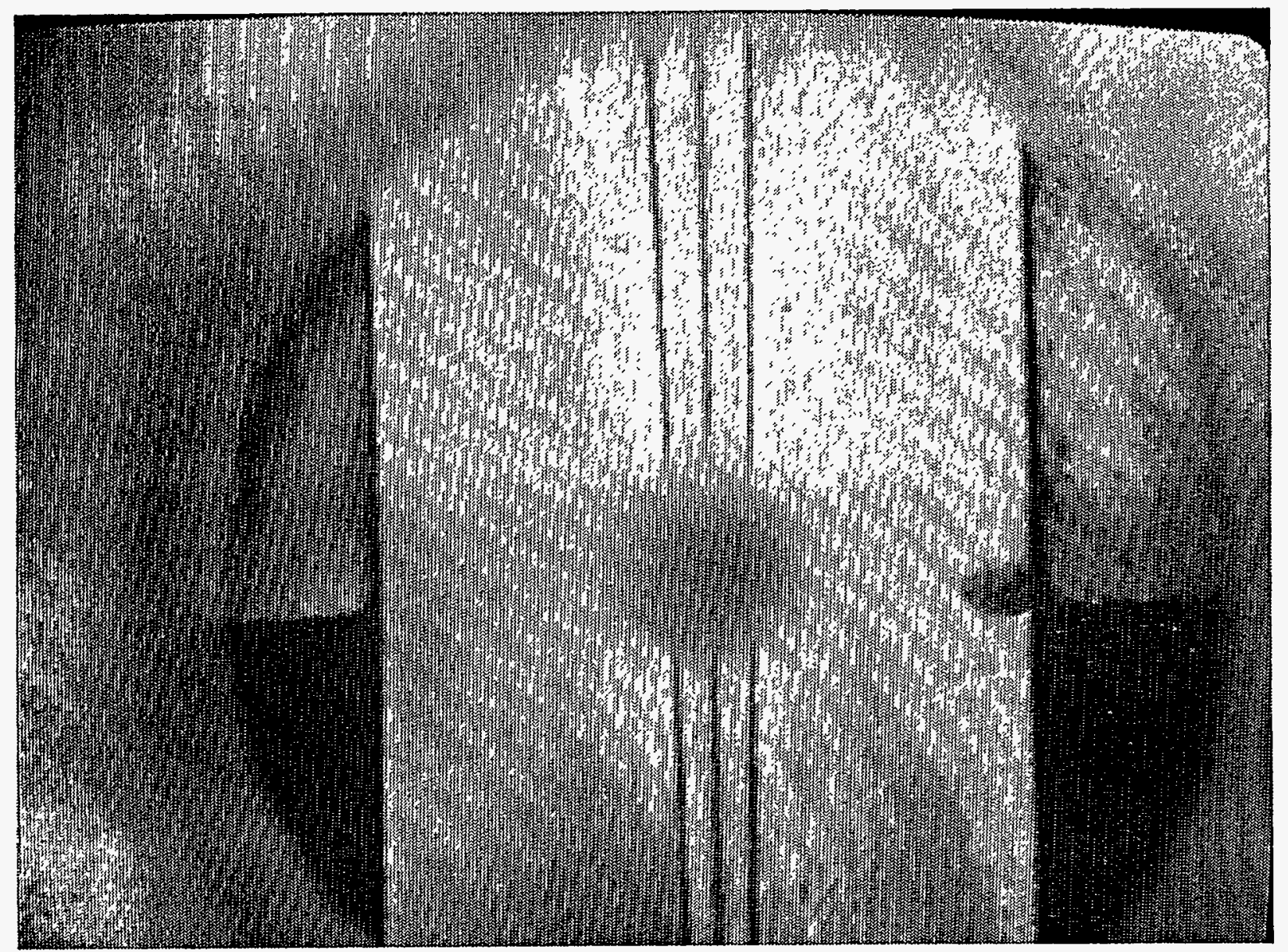

Figure 4. Coaxial View of GTAW Electrode Holder

Preprocessing or signal conditioning is used to enhance the image so that the flange edges can be more easily detected by the image processing computer. The video image analysis performed in this investigation was based on gray scale analysis. Gray scale analysis refers to vision processing based on pixel intensity. The information required for GTAW process control based on flange thickness is an accurate measurement of the combined flange thickness. From Figure 2, the combined flange thickness is equal to $T_{1}+T_{2}$, By using pixel intensities and pixel numbers (from a calibrated video image), the flange thickness can be determined.

A line profile is a report of pixel intensity values $(0-255)$ for every pixel between two selected pixel locations. A graph of a line profile is simply a graph of pixel intensity versus pixel location. Figure 6 shows a line profile across the weld joint above the electrode spot of Figure 4. The three distinct downward spikes in Figure 6 in the center of the graph represent the pixel intensity values for the two outside flange edges and the gap between the weld flanges. The three downward spikes have 
- Knəmoә6 дu!o!

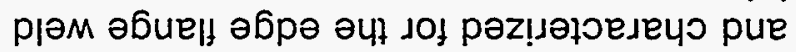

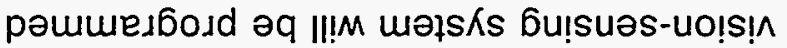

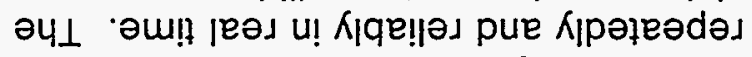

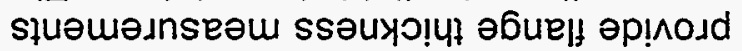

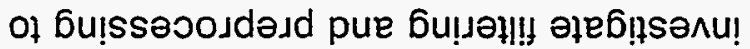

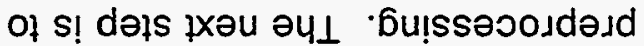

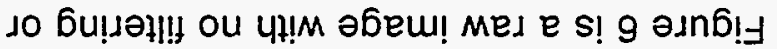

'?ndu!

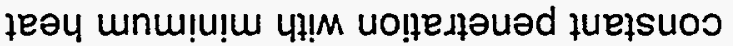
u!efu!eu 아 pəג!nbəd se pəłsn!pe əq

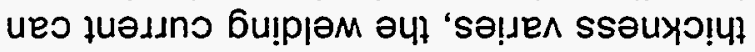

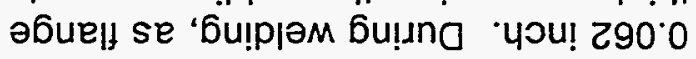

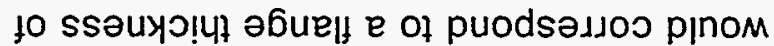

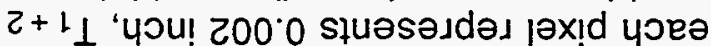

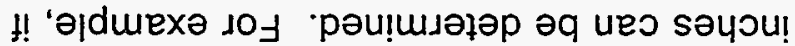

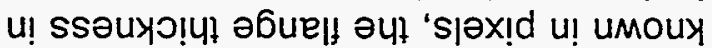

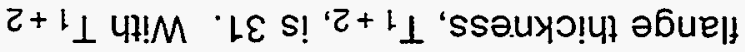

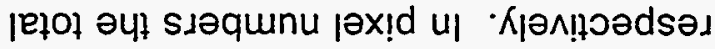

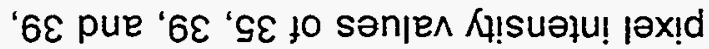
әлеч pue $\varepsilon 9$ pue ' $\angle t$ ' $2 \varepsilon$ әرe $\supset$ x!puədd $\forall$

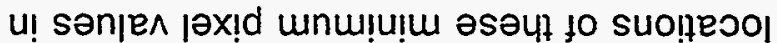

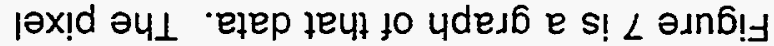
pue ' 9 əנnб!

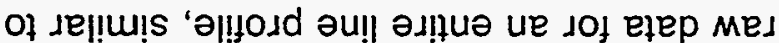

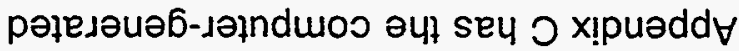

- wayl punose spax!d

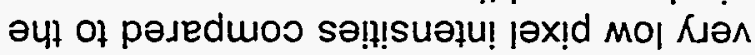

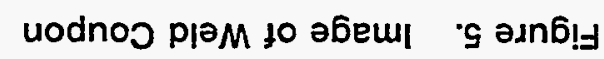

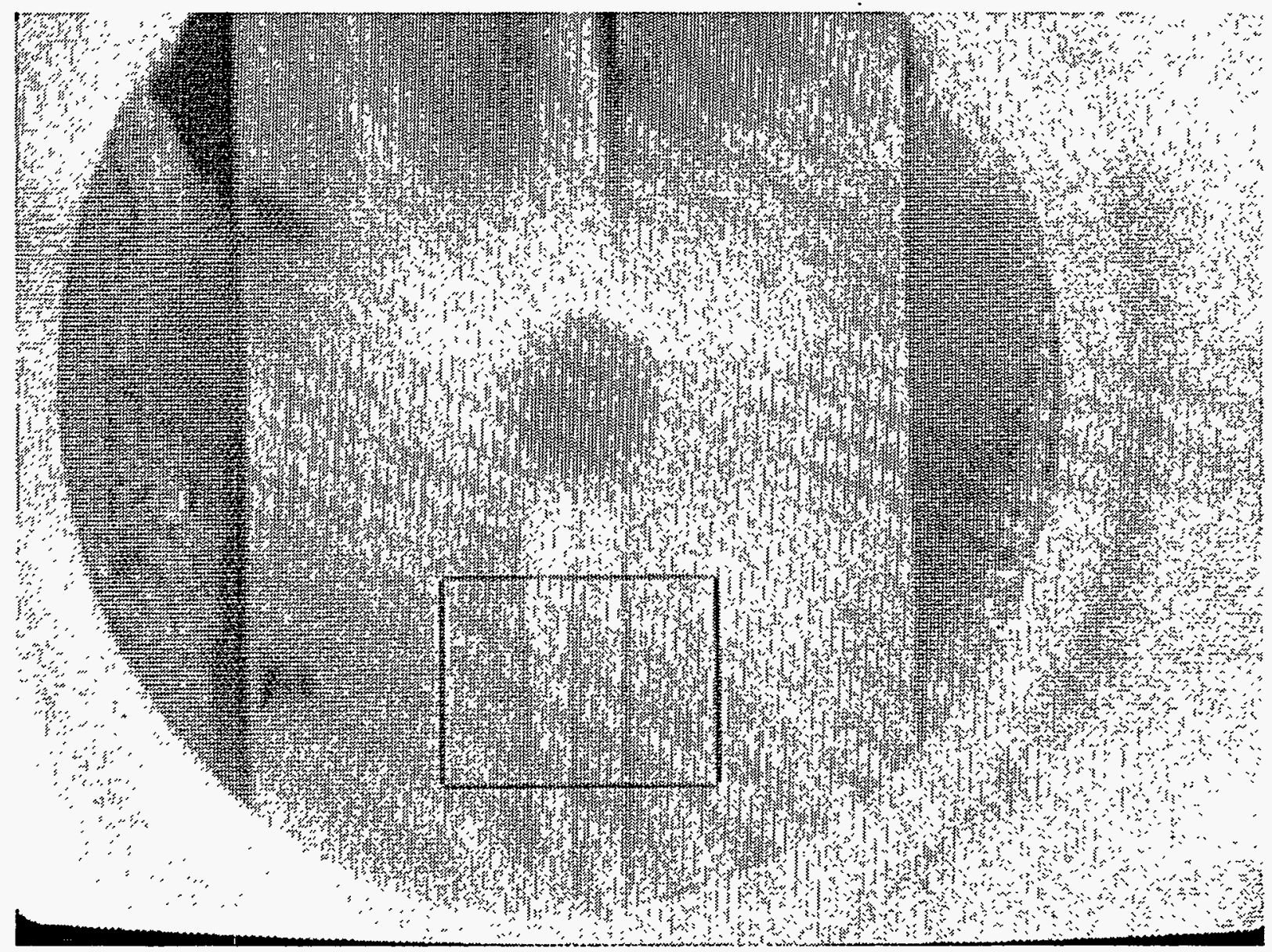




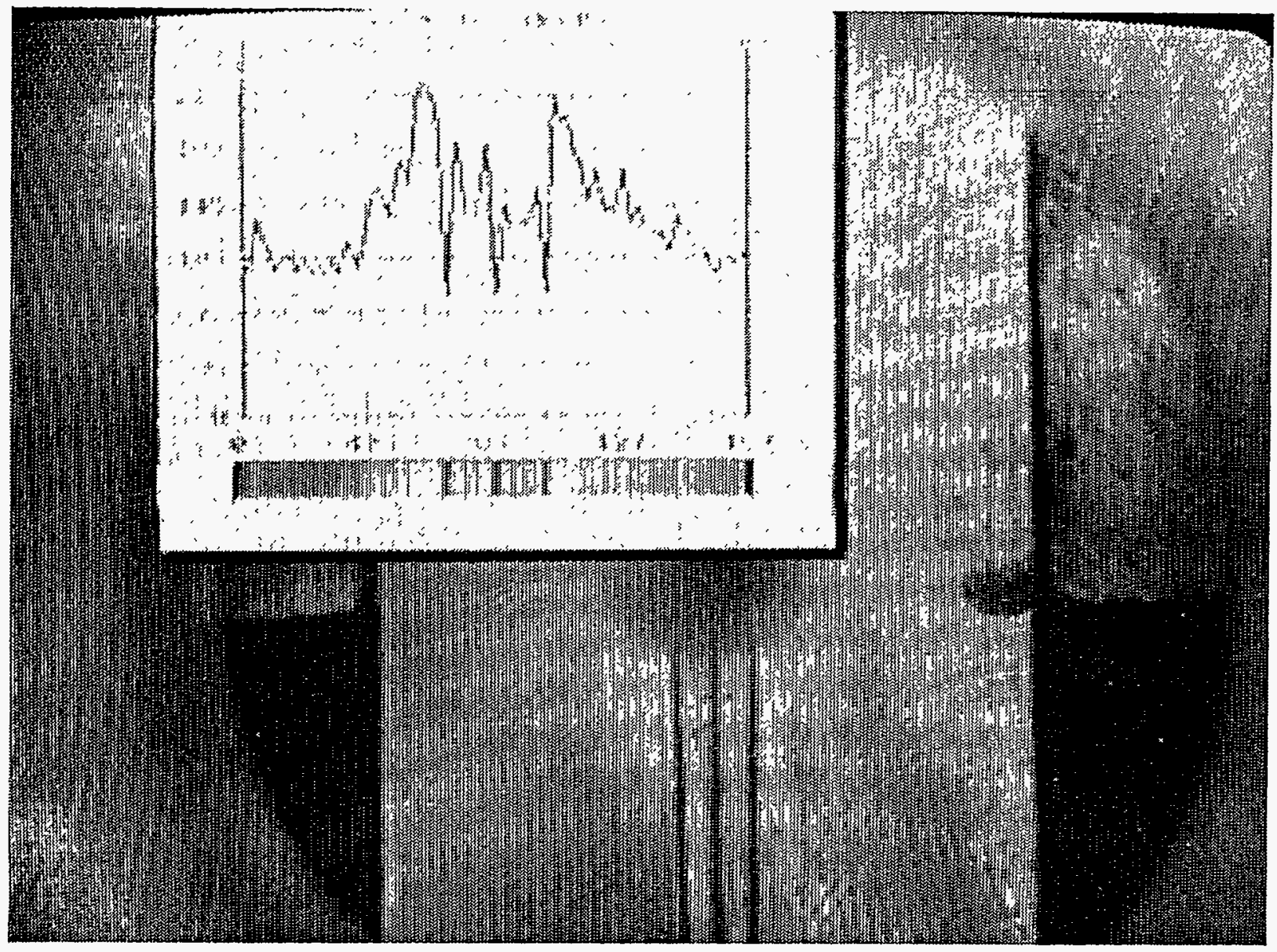

Figure 6. Line Profile Across the Weld Joint Above the Electrode Spot

\section{Accomplishments}

1. The design of the coaxial view GTAW electrode holder was proven acceptable for image processing and obtaining pixel intensity values for measuring total flange thickness.

2. Examples of vision processing methods were investigated with the welding arc present and without the arc. 


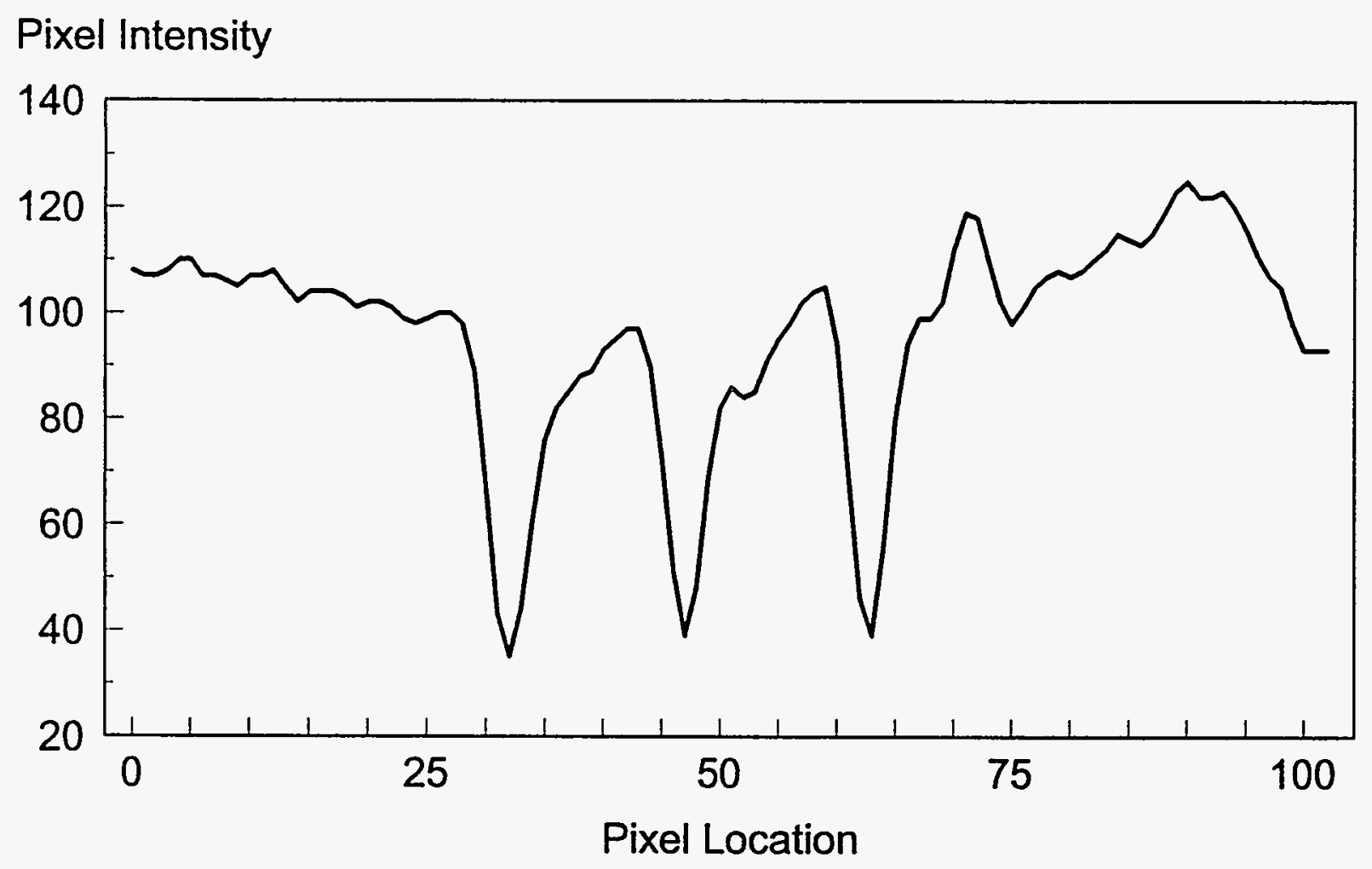

Figure 7. Graph of Line Profile Data Contained in Appendix C 


\section{References}

1R. W. Richardson, D. A. Gutow, R. A. Anderson, and D. A. Farson, "Coaxial Arc Weld Pool Viewing for Process Monitoring and Control," Welding Journal 63 (3), 1984, pp 43-45.

2R. W. Richardson, A Vision-Based Adaptive GTA Welding System for Aerospace Applications, Edison Welding Institute, MR8702, Columbus, Ohio. 


\section{Appendix A}

\section{Image-Pro II Menus}


Image-Pro II

File

Analysis

Filtering

contrast

Operations

Acquire

Measurement

Palette

Editor

User Modules

Scripting

options/Exit

Image-Pro II Main Menu

Image-Pro II

File

Clear Image

Reload Image

Load Image

Save Image

Palette

Editor

User Modules

Scripting

options/Exit

Image-Pro File Menu 


\begin{tabular}{|l|}
\hline Load Image \\
\\
-- TOP -- \\
COLOR1.HFF \\
COLOR2.HFF \\
EDG_BOB.HFF \\
EDG_HORZ.HFF \\
-- DOWn -- \\
OK CANCEL \\
\hline
\end{tabular}

Image-Pro II Load Image Menu

Command Sequence: File

Load Image

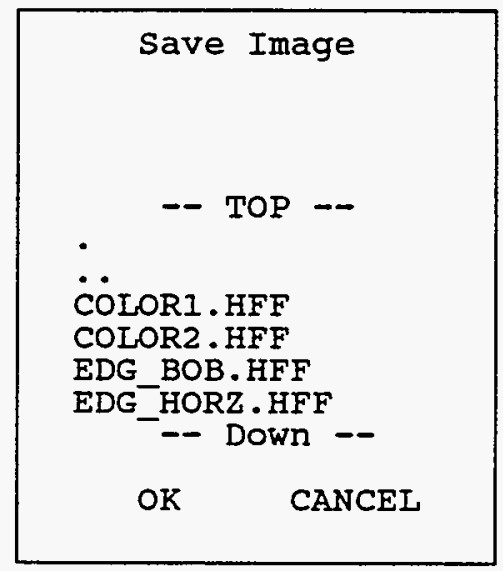

Image-Pro II Save Image Menu

Command Sequence: File

Save Image 


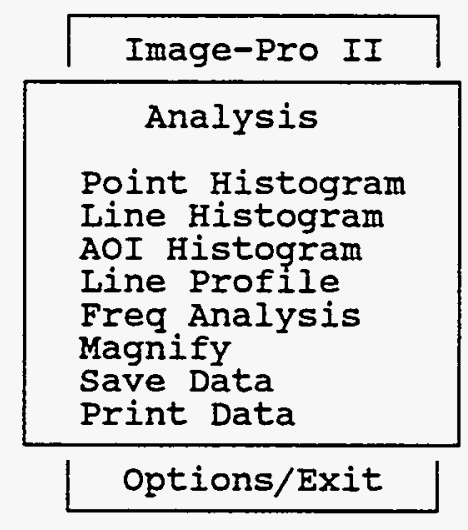

Image-Pro II Analysis Menu
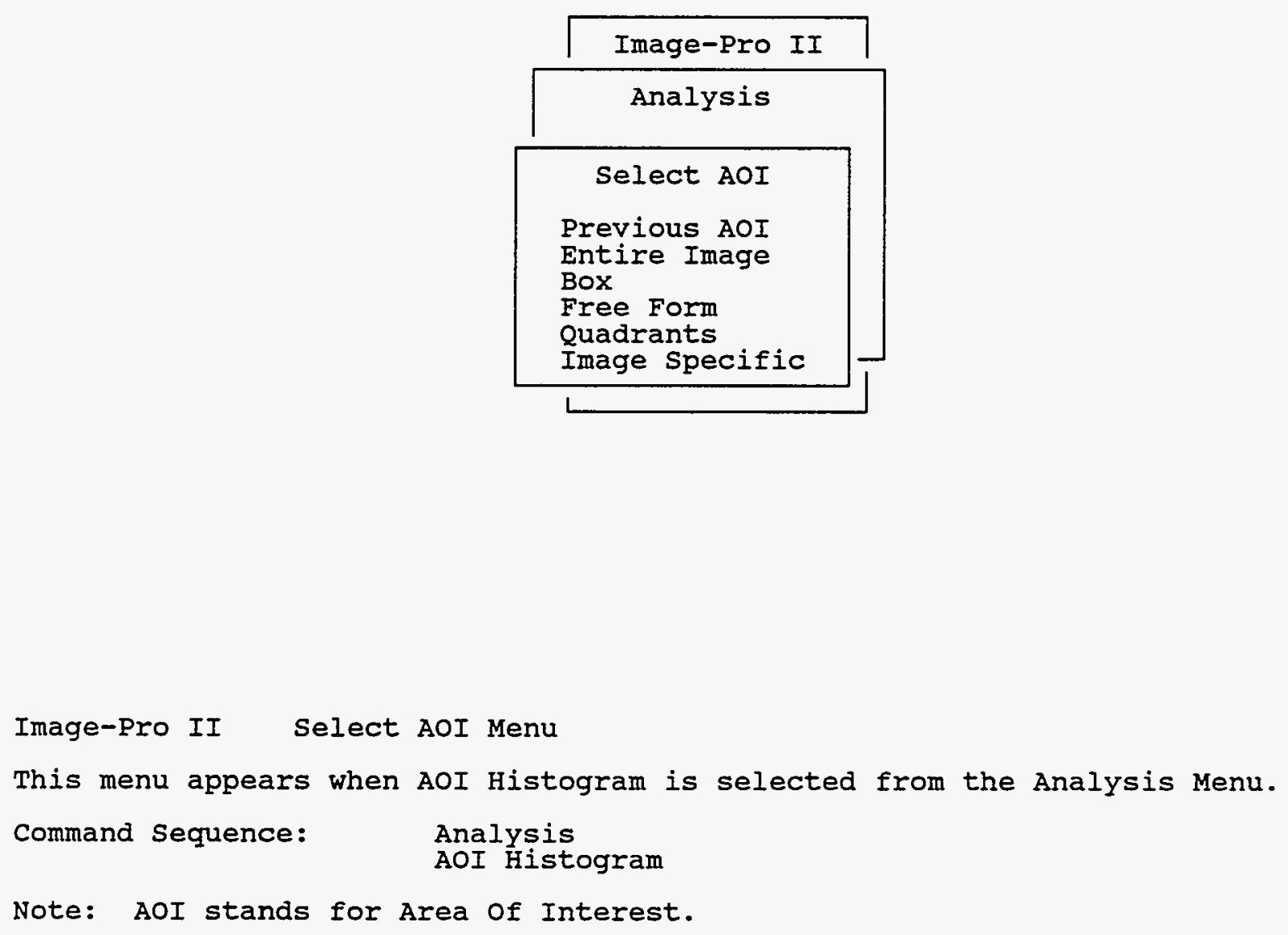


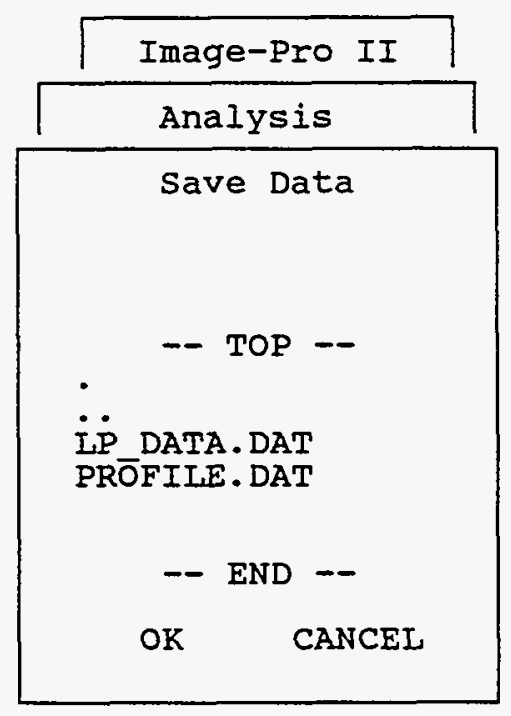

Image-Pro II Save Data Menu

Command Sequence: Analysis

Save Data

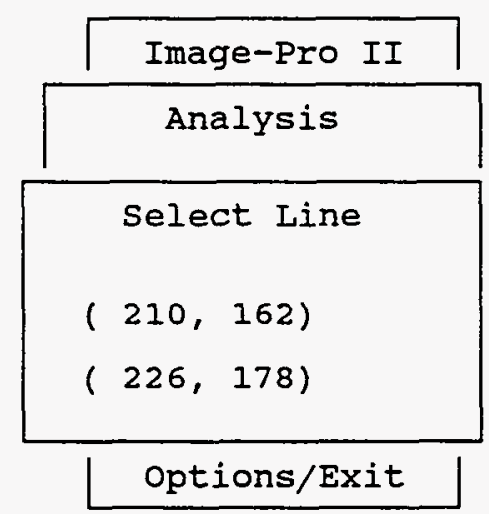

Image-Pro II

This screen appears when Line Profile is selected from the Analysis Menu. Command Sequence: Analysis Line Profile 


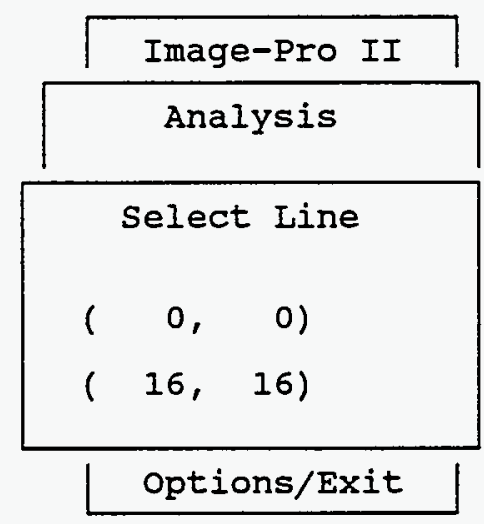

Image-Pro II

This screen appears when Line Histogram is selected from the Analysis Menu. Command Sequence: Analysis Line Histogram

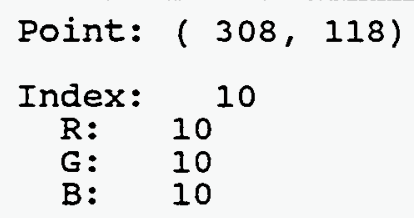

Image-Pro II

This box appears when Point Histogram is selected from the Analysis Menu. Command Sequence: Analysis

Point Histogram 


\begin{tabular}{|l|}
\hline \multicolumn{1}{|c|}{ Image-Pro II } \\
\hline Filtering \\
Sharpen \\
Blur \\
Edge Detect \\
Morphological \\
User Specified \\
Attributes \\
\hline User Modules \\
Scripting \\
Options/Exit \\
\hline
\end{tabular}

Image-Pro II Filtering Menu

\begin{tabular}{|c|}
\hline \multicolumn{1}{|c|}{ Image-Pro II } \\
\hline Filtering \\
\hline Sharpen \\
Hi-Pass \\
Unsharp Mask \\
\hline Attributes \\
\hline $\begin{array}{l}\text { User Modules } \\
\text { Scripting } \\
\text { Options/Exit }\end{array}$ \\
\hline
\end{tabular}

Image-Pro II Sharpen Menu

Command Sequence: Filtering

Sharpen 


\begin{tabular}{|c|c|}
\hline \multicolumn{2}{|c|}{ Image-Pro II } \\
\hline \multicolumn{2}{|c|}{ Filtering } \\
\hline Blur & \\
\hline $\begin{array}{l}\text { Lo-Pass } \\
\text { Median }\end{array}$ & $\begin{array}{l}\text { ect } \\
\text { gical }\end{array}$ \\
\hline \multicolumn{2}{|c|}{ Attributes } \\
\hline \multicolumn{2}{|c|}{$\begin{array}{l}\text { User Modules } \\
\text { Scripting } \\
\text { Options/Exit }\end{array}$} \\
\hline
\end{tabular}

Image-Pro II Blur Menu

After a Blur option is selected, the "Select AOI" menu is displayed.

Command Sequence: Filtering Blur

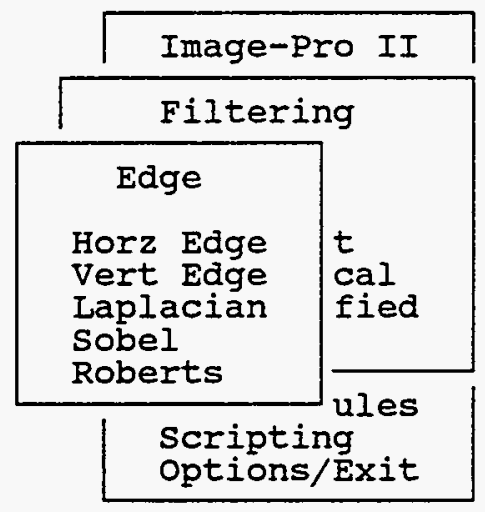

Image-Pro II Edge Detect Menu

After Edge Detect option is selected, the "Select AOI" menu is displayed.

Command Sequence: Filtering

Edge Detect 


\begin{tabular}{|l|}
\hline \multicolumn{1}{|c|}{ Image-Pro II } \\
\hline \multicolumn{1}{|c|}{ Filtering } \\
\hline Morphological \\
Erosion \\
Dilation \\
\hline Attributes \\
\hline $\begin{array}{l}\text { User Modules } \\
\text { Scripting } \\
\text { Options/Exit }\end{array}$ \\
\hline
\end{tabular}

Image-Pro II Morphological Menu

Command Sequence: $\quad$ Filtering

Morphological

After Morphological option is selected, the "Select AOI" menu is displayed.

\begin{tabular}{|c|}
\hline \multicolumn{1}{|c|}{ Image-Pro II } \\
\hline Filtering \\
\hline Attributes \\
Filter Size \\
Filter Scale \\
Filter Boost \\
\hline L d \\
\hline $\begin{array}{l}\text { User Modules } \\
\text { Scripting } \\
\text { Options/Exit }\end{array}$ \\
\hline
\end{tabular}

Image-Pro II Attributes Menu

Command Sequence: Filtering

Attributes 


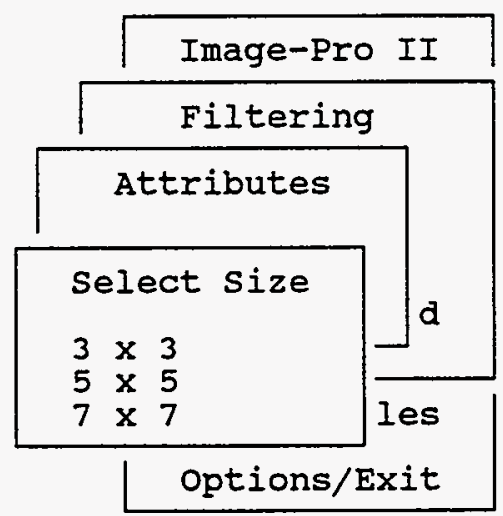

Image-Pro II Filter Size Menu

Command Sequence: $\quad$ Filtering

Attributes
Filter Size

After Filter size is selected, user is returned to the Filtering menu.

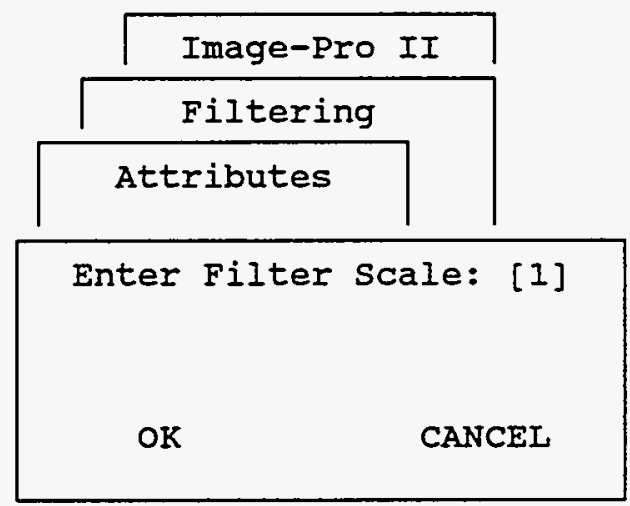

$\begin{array}{ll}\text { Image-Pro II } & \text { Filter scale Menu } \\ \text { Command sequence: } & \text { Filtering } \\ & \text { Attributes } \\ & \text { Filter Scale }\end{array}$

After Filter scale is selected, user is returned to Filtering menu. 


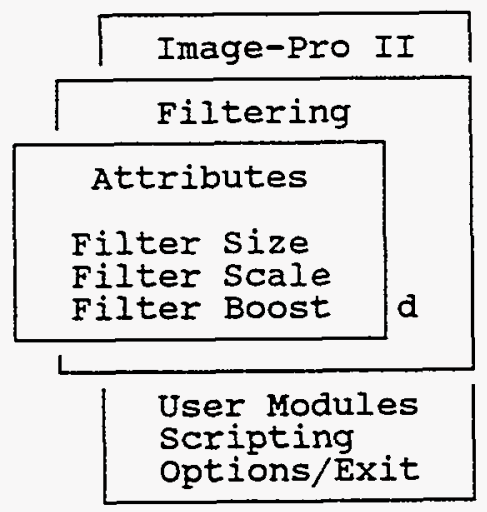

Inage-Pro II Filter Boost Menu

Command sequence: $\quad$ Filtering Attributes

Filter Boost

After Filter Boost is entered, user is returned to Filtering menu.

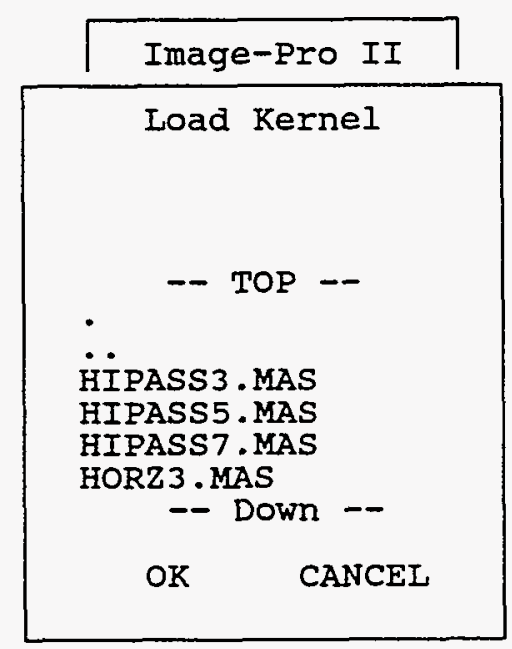

Image-Pro II Load Kernel Menu
Command Sequence: $\quad$ Filtering
User Specified
Load Kernel

After kernel is selected, select AOI menu is displayed. After AOI is selected, user is returned to Filtering menu. 


\begin{tabular}{|l|}
\hline \multicolumn{1}{|c|}{ Image-Pro II } \\
\hline \multicolumn{1}{|c|}{ Contrast } \\
Sidie/stretch \\
Equalize \\
Contour \\
Threshhold \\
Index Replace \\
Index Shift \\
Transform \\
\hline $\begin{array}{l}\text { Scripting } \\
\text { Options/Exit }\end{array}$ \\
\hline
\end{tabular}

Image-Pro II contrast Menu

Command Sequence: Contrast

\begin{tabular}{|l|}
\hline \multicolumn{1}{|c|}{ Image-Pro II } \\
\hline Operations \\
Composite \\
Combine \\
Posterize \\
Replicate \\
Rotate \\
Scale \\
Unary \\
\hline Scripting \\
Options/Exit \\
\hline
\end{tabular}

Image-Pro II Operations Menu

Command Sequence: Operations

Note: The Select AOI menu appears when the Rotate, Scale, Posterize, and Unary options are selected. 


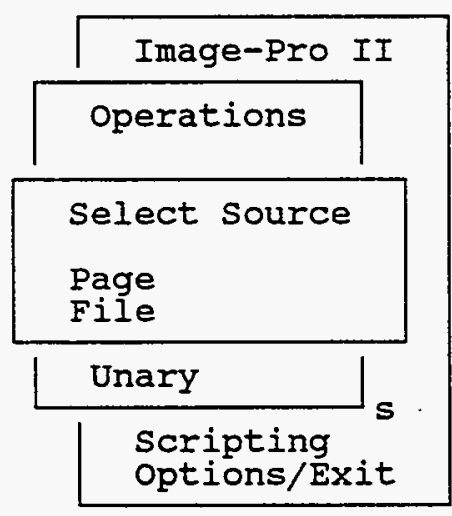

Image-Pro II select Source Menu

Command Sequence: Operations

Combine

select source

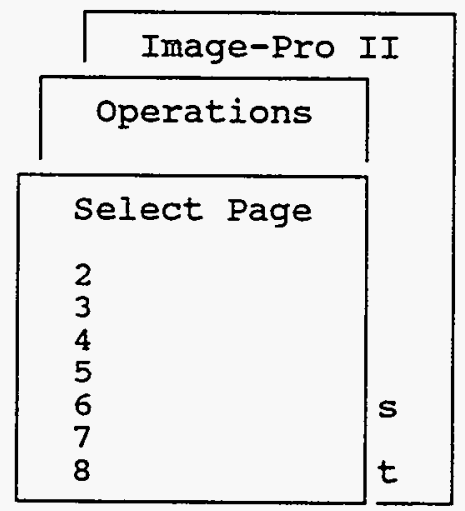

Image-Pro II Select Page

Command Sequence: Operations

Combine

select source

Select Page

After the Page is selected, the select AOI screen is displayed. 


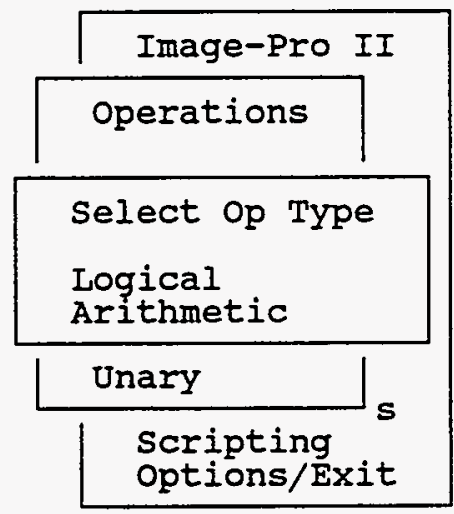

$\begin{array}{ll}\text { Image-Pro II } \quad \text { Select op Type Menu } \\ \text { Command Sequence: } & \text { Operations } \\ & \text { Combine } \\ & \text { Select Source } \\ & \text { Select Page } \\ & \text { Select AOI } \\ & \text { Select Op Type }\end{array}$




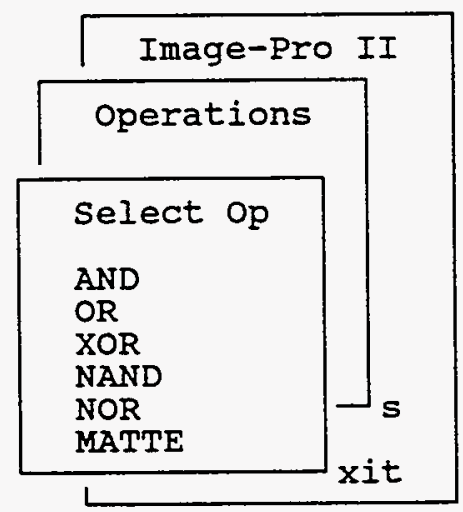

$\begin{array}{ll}\text { Image-Pro II } \quad \text { Select } & \text { Op Menu } \\ \text { Command Sequence: } & \text { Operations } \\ & \text { Select Source } \\ & \text { Select Page } \\ & \text { select AOI } \\ & \text { Select Op Type } \\ \text { Logical } & \text { Select op }\end{array}$

After one of the select op options is selected, the user is returned to the Operations menu. 


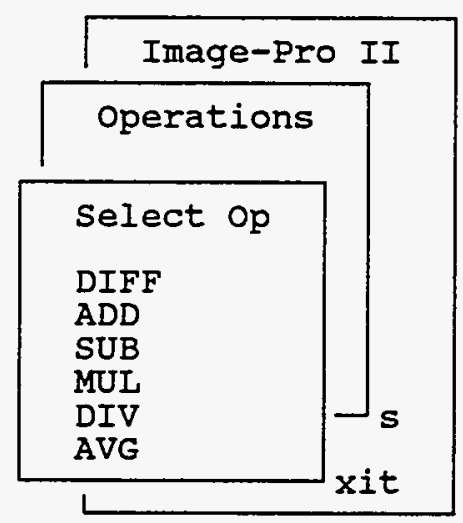

Image-Pro II

This menu appears when the select op Type $\rightarrow$ Arithmetic is selected.

Command Sequence:

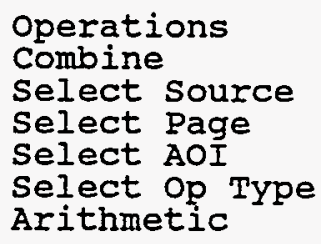

After the op Type of Arithmetic is selected, the same select op menu that appears for op Type Logical is displayed.

\begin{tabular}{|c|}
\hline Image-Pro II \\
\hline Select File \\
\\
-- TOP -- \\
COLOR1.HFF \\
COLOR2.HFF \\
EDG_BOB.HFF \\
EDG_HORZ.HFF \\
-- DOWn -- \\
OK CANCEL \\
\end{tabular}

Image-Pro II select File Menu

Command Sequence: Operations

select File

After a file is selected, the select AOI menu is displayed. 


\begin{tabular}{|c|}
\hline Image-Pro II \\
\hline Combine File \\
\\
-- TOP -- \\
- \\
COLOR1.HFF \\
COLOR2.HFF \\
EDG_BOB.HFF \\
EDG_HORZ.HFF \\
- DOWn -- \\
OK CANCEL \\
\hline
\end{tabular}

Image-Pro II Combine File Menu

Command Sequence: Operations

combine

Select source

File

Combine File

After a Combine File is selected, the sequence is the same with the Select Page: Select AOI Select op Type

Logical or Arithmetic

Select op

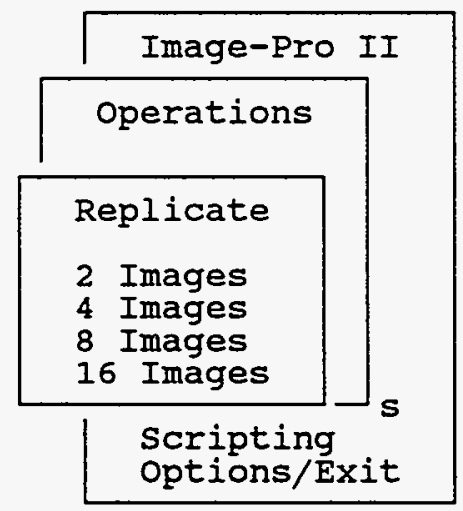

Image-Pro II Replicate Menu

Command Sequence: Operations

Replicate

After Replicate option is selected, user is returned to operations menu. 


\begin{tabular}{|l|}
\hline \multicolumn{1}{|c|}{ Image-Pro II } \\
\hline Acquire \\
Single Frame \\
Continuous \\
Attributes \\
\hline Measurement \\
Palette \\
Editor \\
User Modules \\
Scripting \\
Options/Exit \\
\hline
\end{tabular}

Image-Pro Acquire Menu

Command Sequence: Acquire

When Single Frame or Continuous is selected, the user is returned to the Acquire menu.

\begin{tabular}{|c|c|c|}
\hline & \multicolumn{2}{|c|}{ Image-Pro II } \\
\hline \multicolumn{3}{|c|}{ Acquire } \\
\hline & -ibutes & e \\
\hline & era LUT & \\
\hline & \multicolumn{2}{|c|}{$\begin{array}{l}\text { Measurement } \\
\text { Palette } \\
\text { Editor } \\
\text { User Modules } \\
\text { Scripting } \\
\text { Options/Exit }\end{array}$} \\
\hline
\end{tabular}

Image-Pro II Attributes Menu

Command Sequence: Acquire

Attributes 


\begin{tabular}{|l|}
\hline Select Curve \\
- TOP -- \\
- T \\
GAMMA12. IUT \\
GAMMA14. IUT \\
GAMMA16. IUT \\
GAMMA18. IUT \\
-- DOWM -- \\
OK CANCEL \\
\hline
\end{tabular}

Image-Pro II

Select Curve Menu

Command Sequence: Acquire

Attributes

Camera LUT

Select Curve

After Curve is selected, user is returned to Acquire Menu.

\begin{tabular}{|l|}
\hline \multicolumn{1}{|c|}{ Image-Pro II } \\
\hline Measurement \\
Measure Iine \\
Measure Trace \\
Measure Angle \\
Calibrate \\
Save Trace \\
Print Trace \\
\hline User Modules \\
Scripting \\
Options/Exit \\
\hline
\end{tabular}

Image-Pro II Measurement Menu

Command Sequence: Measurement 


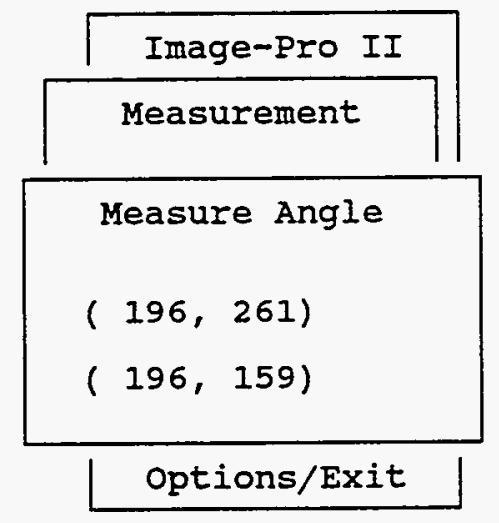

Angle

90.00

Image-Pro II Measure Angle Screen

Command Sequence: Measurement

Measure Angle

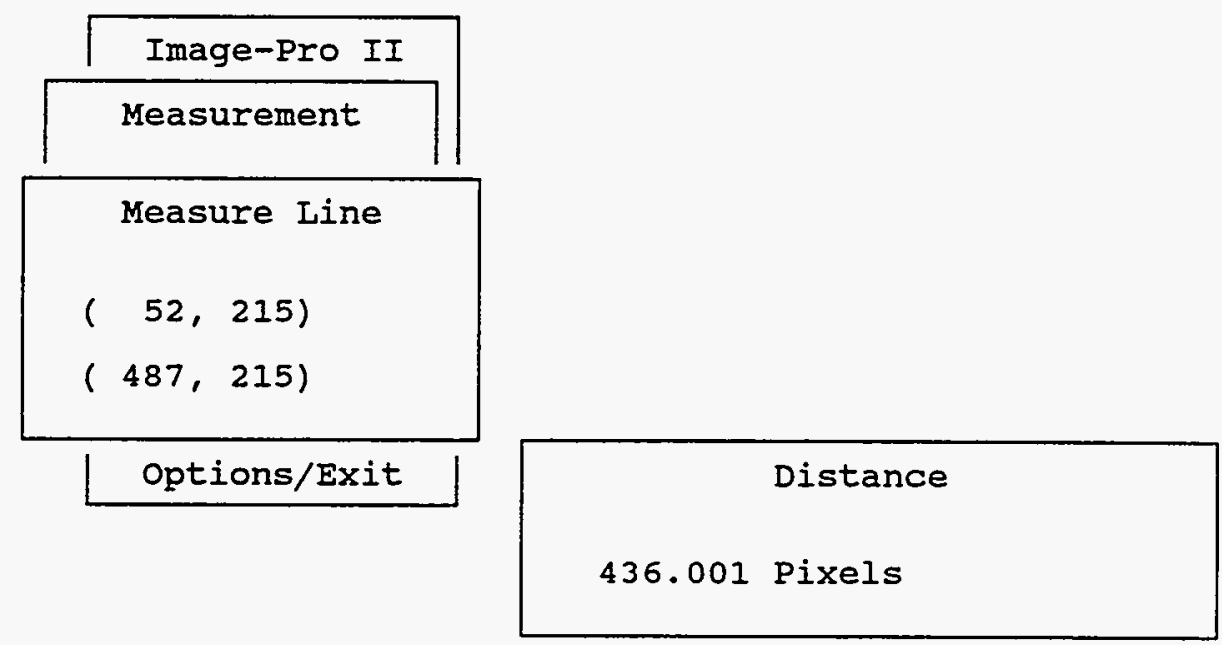

Image-Pro II Measure Line Screen

Command Sequence:

Measurement

Measure Line 


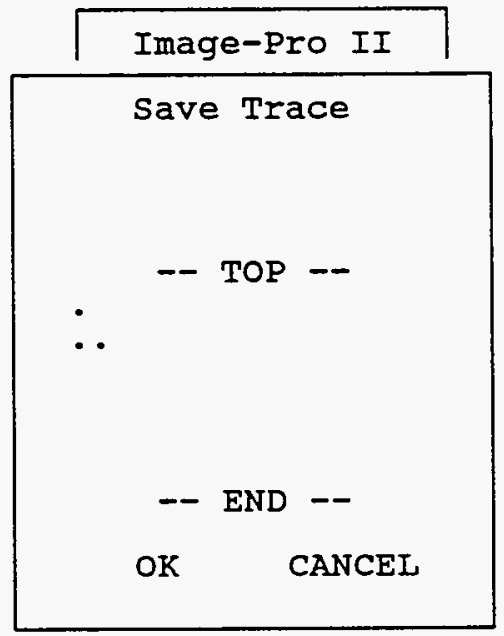

Image-Pro II Save Trace Screen

Command Sequence: Measurement

Save Trace

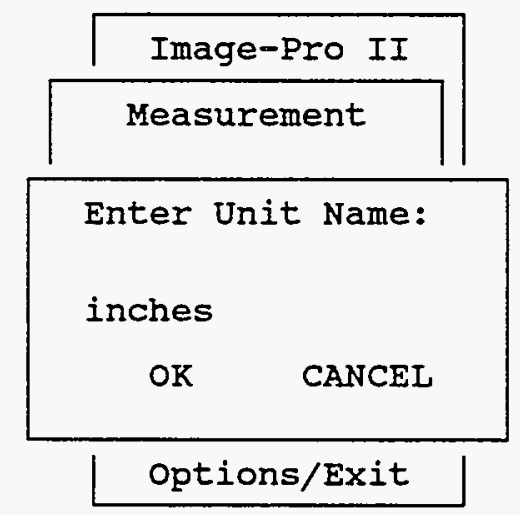

Image-Pro II Calibrate Screer

Command Sequence: Measurement

Calibrate 


\begin{tabular}{|l|}
\hline Image-Pro II \\
\hline Calibrate \\
$(170,153)$ \\
$(269,282)$ \\
$\mid$ Options/Exit \\
\hline
\end{tabular}

Image-Pro II Calibrate screen 2

This screen appears after the units are entered in the first calibrate screen.

Command Sequence:

Measurement

Calibrate

(Enter Units)

\begin{tabular}{|l|}
\hline \multicolumn{1}{|c|}{ Image-Pro II } \\
\hline \multicolumn{1}{|c|}{ Palette } \\
Display Palette \\
Edit Palette \\
Edit Screen Index \\
Load Palette \\
Save Palette \\
\hline Editor \\
User Modules \\
Scripting \\
Options/Exit \\
\hline
\end{tabular}

Image-Pro II Palette Menu

Command Sequence: Palette 


\begin{tabular}{|l|}
\hline User Modules \\
File Converter \\
Kernel Editor \\
Print Module \\
Report Generator \\
Utilities \\
Cineloop \\
Image Swap \\
\hline
\end{tabular}

Image-Pro II User Modules Menu
Command Sequence: User Modules

Utilities
Catalog Files
Delete Files
Copy Files
Rename Files
Free Space
Options/Exit

Image-Pro II Utilities Menu

Command Sequence: User Modules

Utilities 


\begin{tabular}{l} 
Cineloop \\
File \\
Show \\
Create \\
Edit \\
Options/Exit \\
\hline
\end{tabular}

$\begin{array}{ll}\text { Image-Pro II Cineloop Menu } & \\ \text { Command Sequence: } & \begin{array}{l}\text { User Modules } \\ \text { CineLoop }\end{array}\end{array}$

Image Swap

Flip Hi/Lo Options/Exit

Imaǵge-Pro II Image Swap Menu

Command Sequence: User Modules

Image Swap 


\begin{tabular}{|l|}
\hline \multicolumn{1}{|c|}{ Image-Pro II } \\
\hline Scripting \\
Record Mode \\
Record Script \\
Stop Script \\
Play Script \\
\hline Palette \\
Editor \\
User Modules \\
Scripting \\
Options/Exit \\
\hline
\end{tabular}

Image-Pro II Scripting Menu

Command Sequence: Scripting

\begin{tabular}{|l|}
\hline Image-Pro II \\
\hline Options \\
Select Page \\
Report Location \\
Color Model \\
Define Image AOI \\
Exit \\
\hline Editor \\
User Modules \\
Scripting \\
Options/Exit \\
\hline
\end{tabular}

Image-Pro II Options/Exit Menu

Command Sequence: Options/Exit 


\section{Appendix B}

Examples of Vision Processing Operations Performed on Coaxially Viewed Images 
Appendix $B$ contains examples of various vision processing operations performed on coaxially viewed images, with and without filtering, with and without the arc present.

NOTE: All line profiles were taken in the area above the torch (in the direction of the torch's travel).

Image processing hardware used to acquire and process these images were

- Data Translation DT2861 Arithmetic Frame Grabber

- Data Translation DT2858 Auxiliary Frame Processor.

Image processing software used to acquire and process these images was

- Image-Pro II by Media Cybernetics.

NOTE: Weld3 is the filename for the frame of the coupon with varying flange thickness (arc off).

NOTE: Weld8 is the filename for the frame of the coupon with varying flange thickness (arc on). 


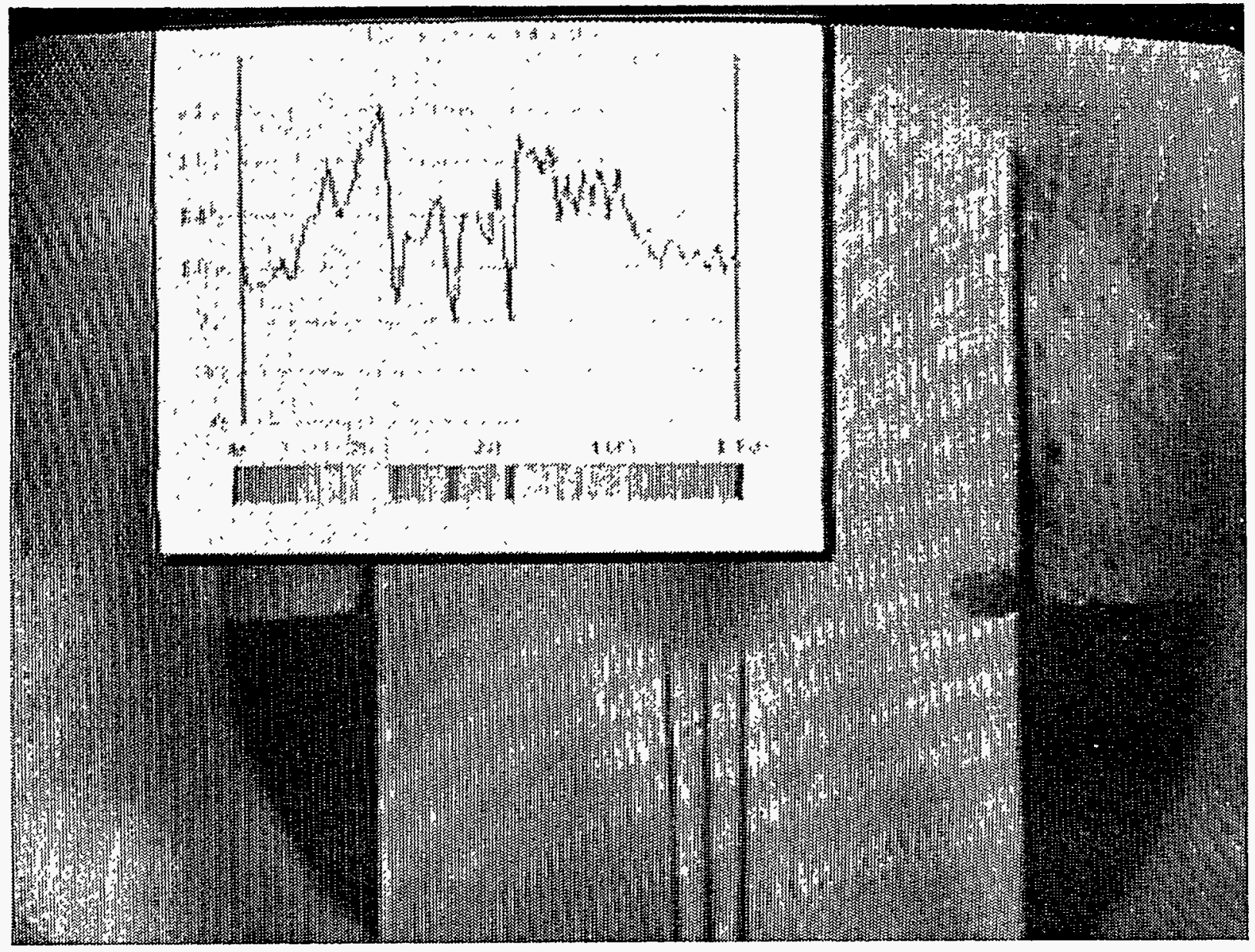

Photo \#3, Weld3, Line Profile 


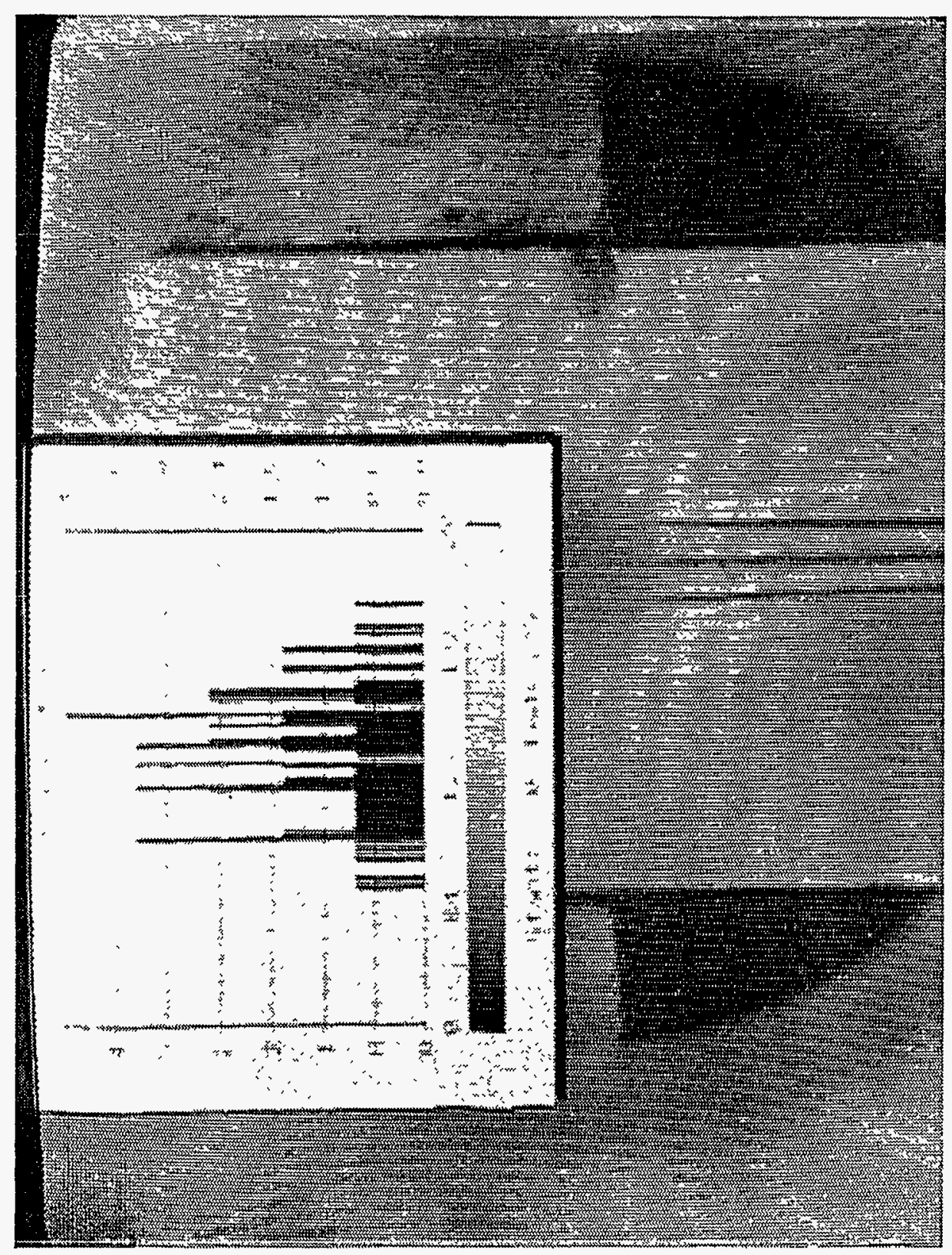

ㅇ

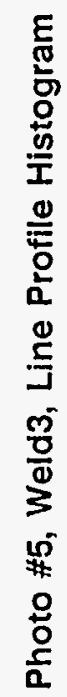




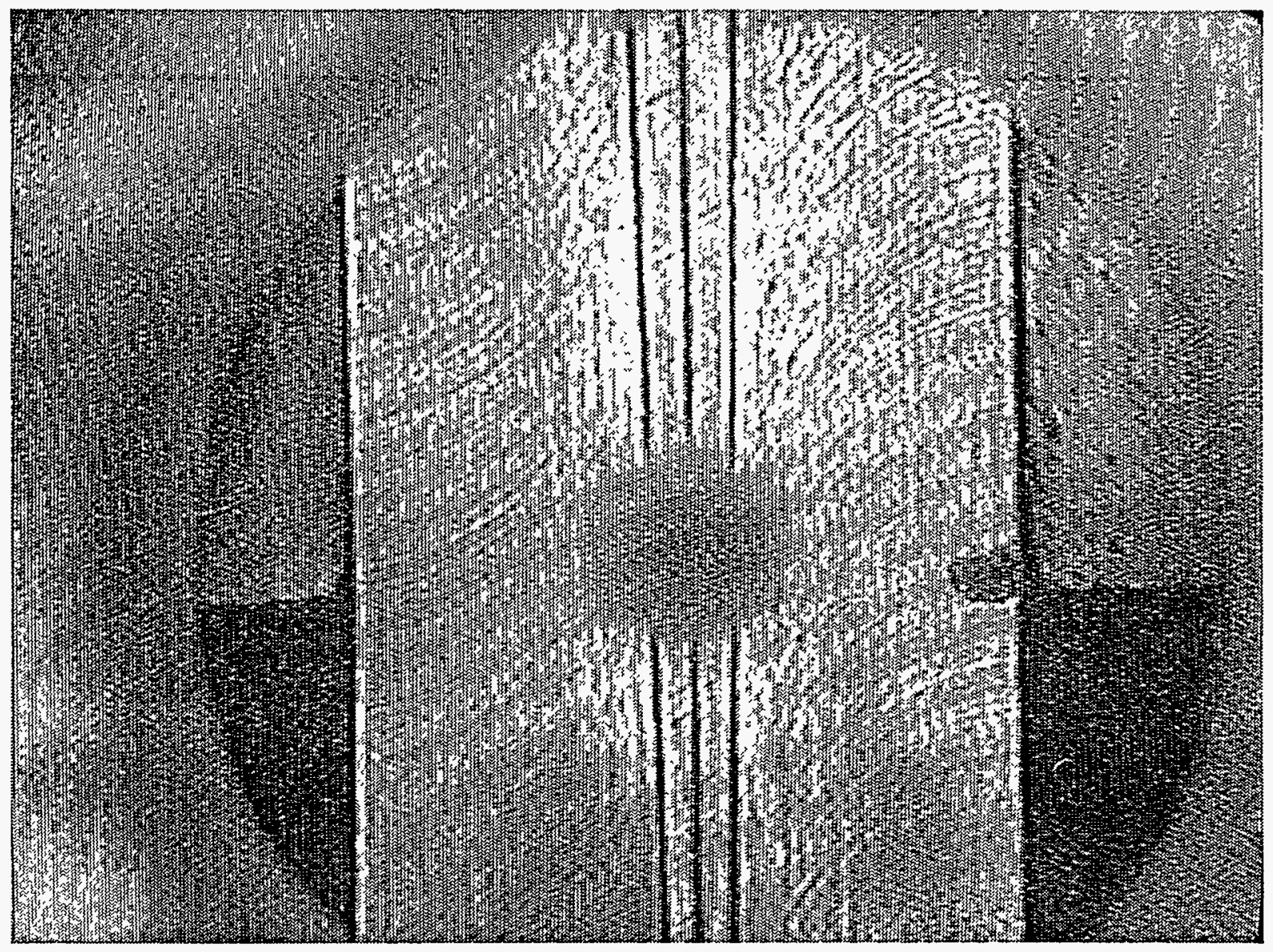

Photo \#7, Weld3, Filtered, Sharpen, Hipass

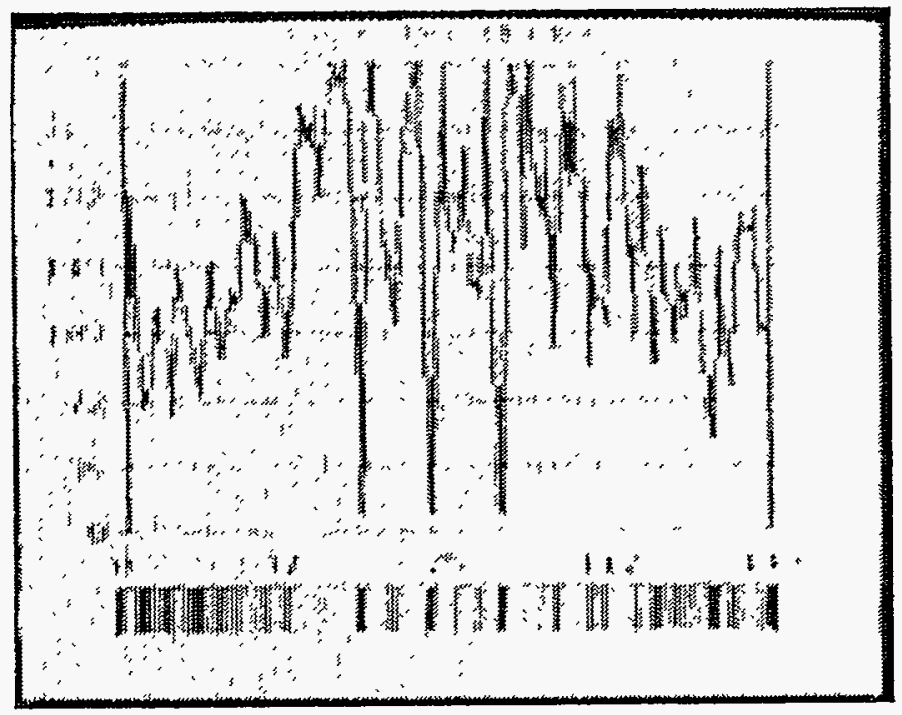

Photo \#8, Weld3, Filtered, Sharpen, Hipass Line Profile 


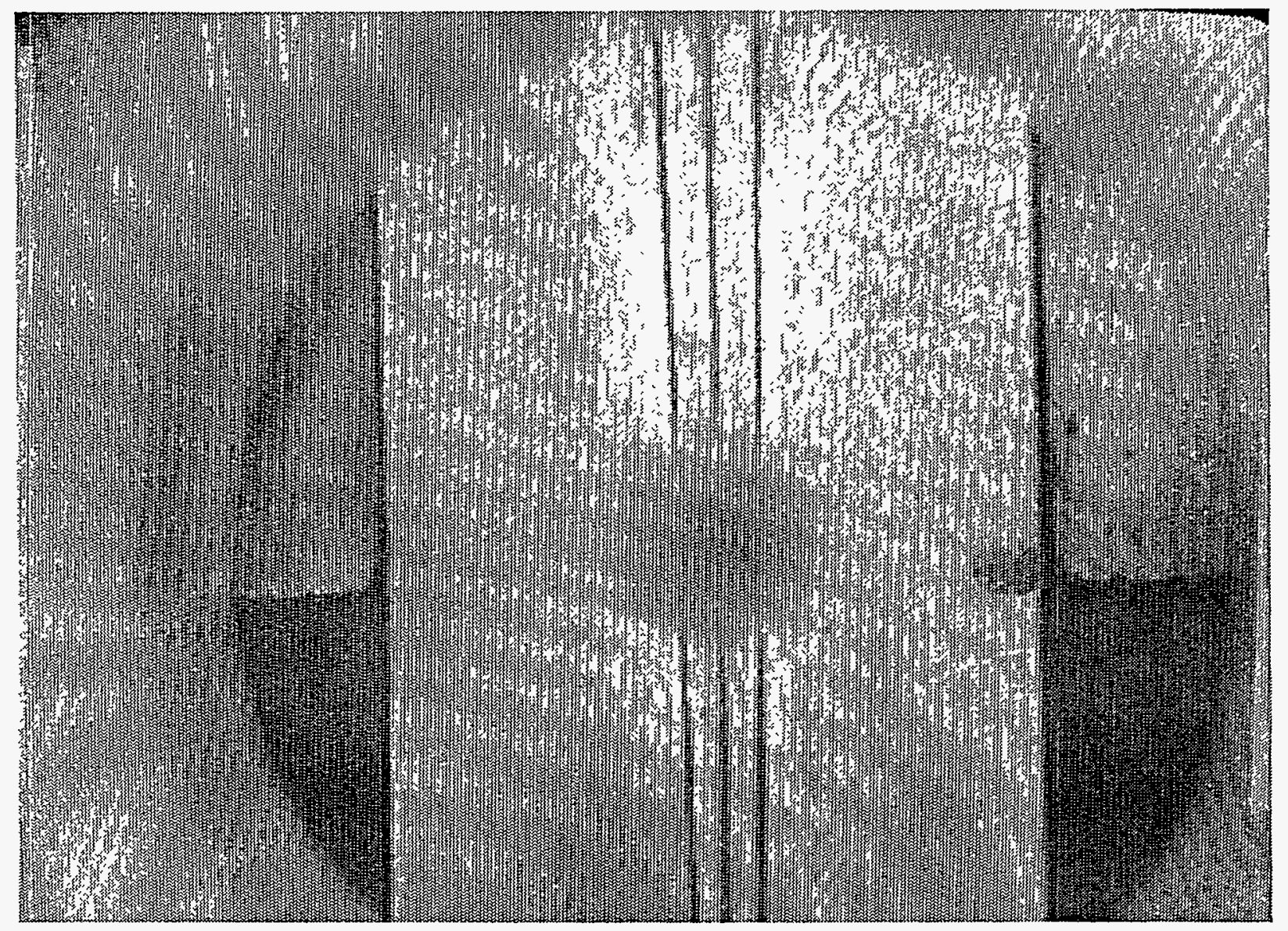

Photo \#9, Weld3, Filtered, Sharpen, Unsharp Mask

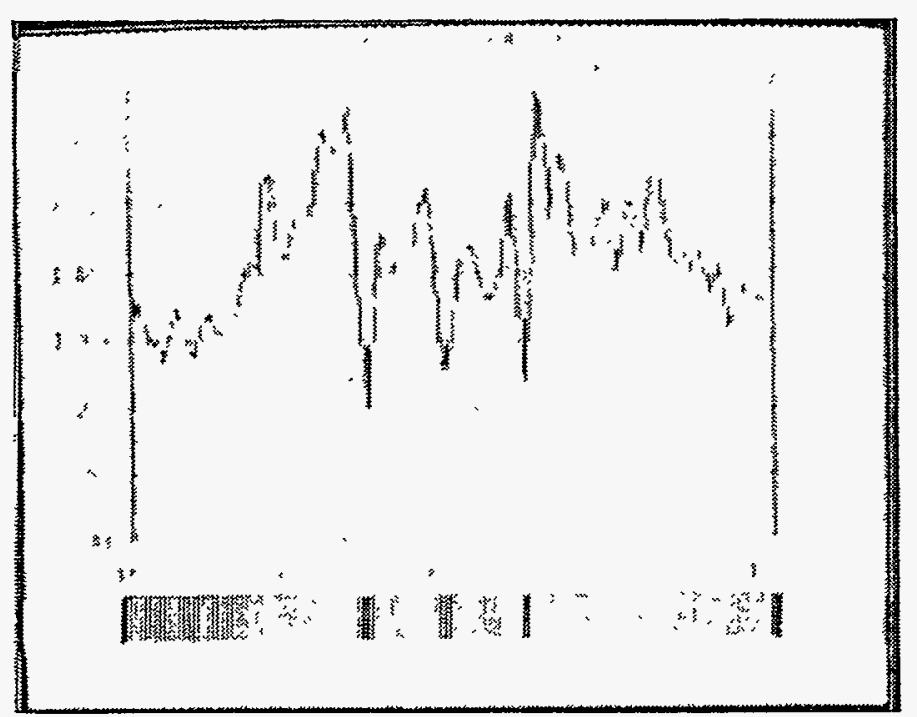

Photo \#10, Weld3, Filtered, Sharpen, Unsharp Mask Line Profile 


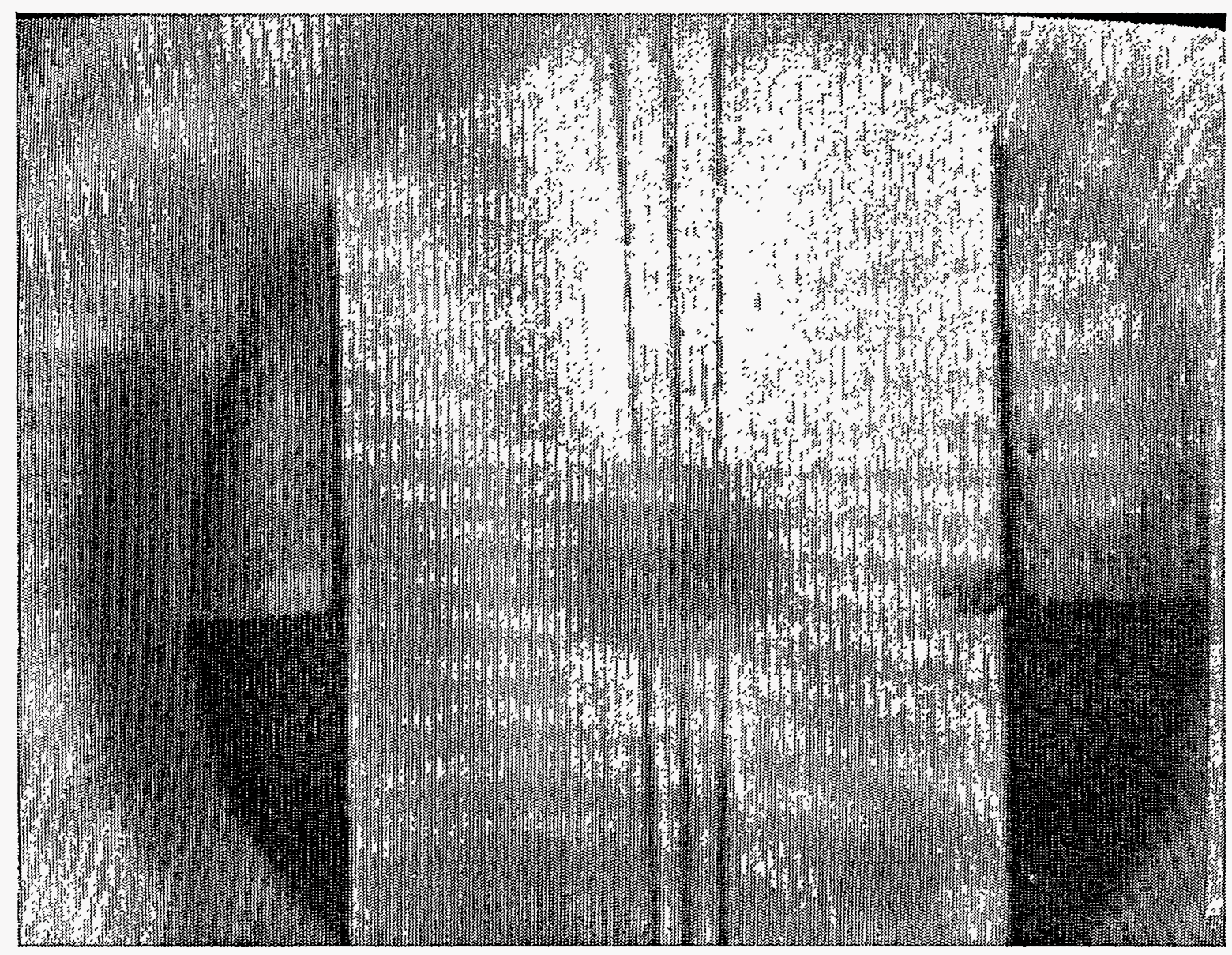

Photo \#11, Weld3, Filtered, Blur, Lopass

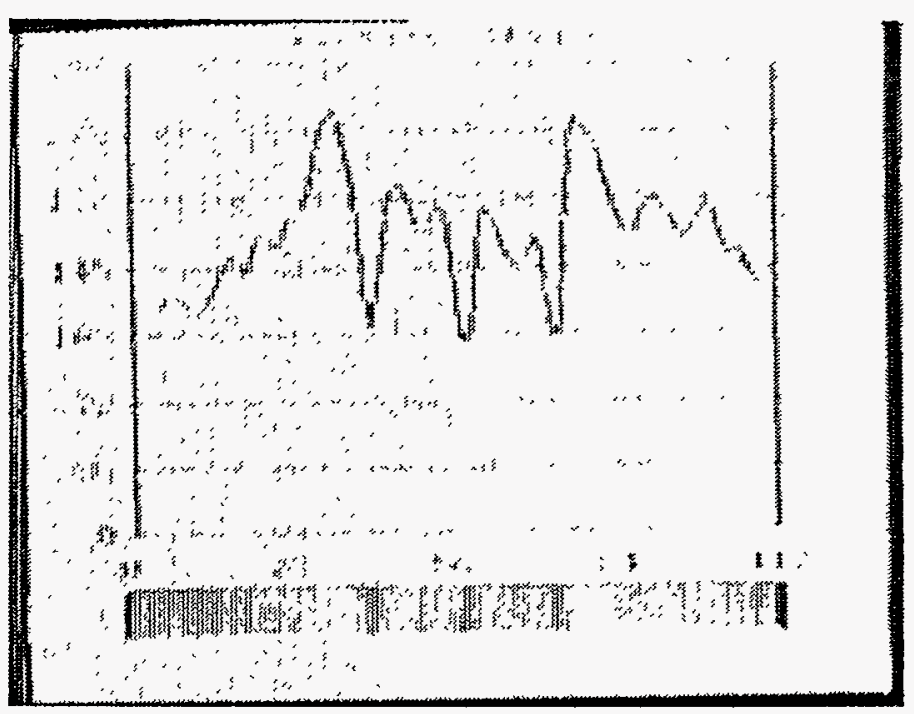

Photo \#12, Weld3, Filtered, Blur, Lopass Line Profile 


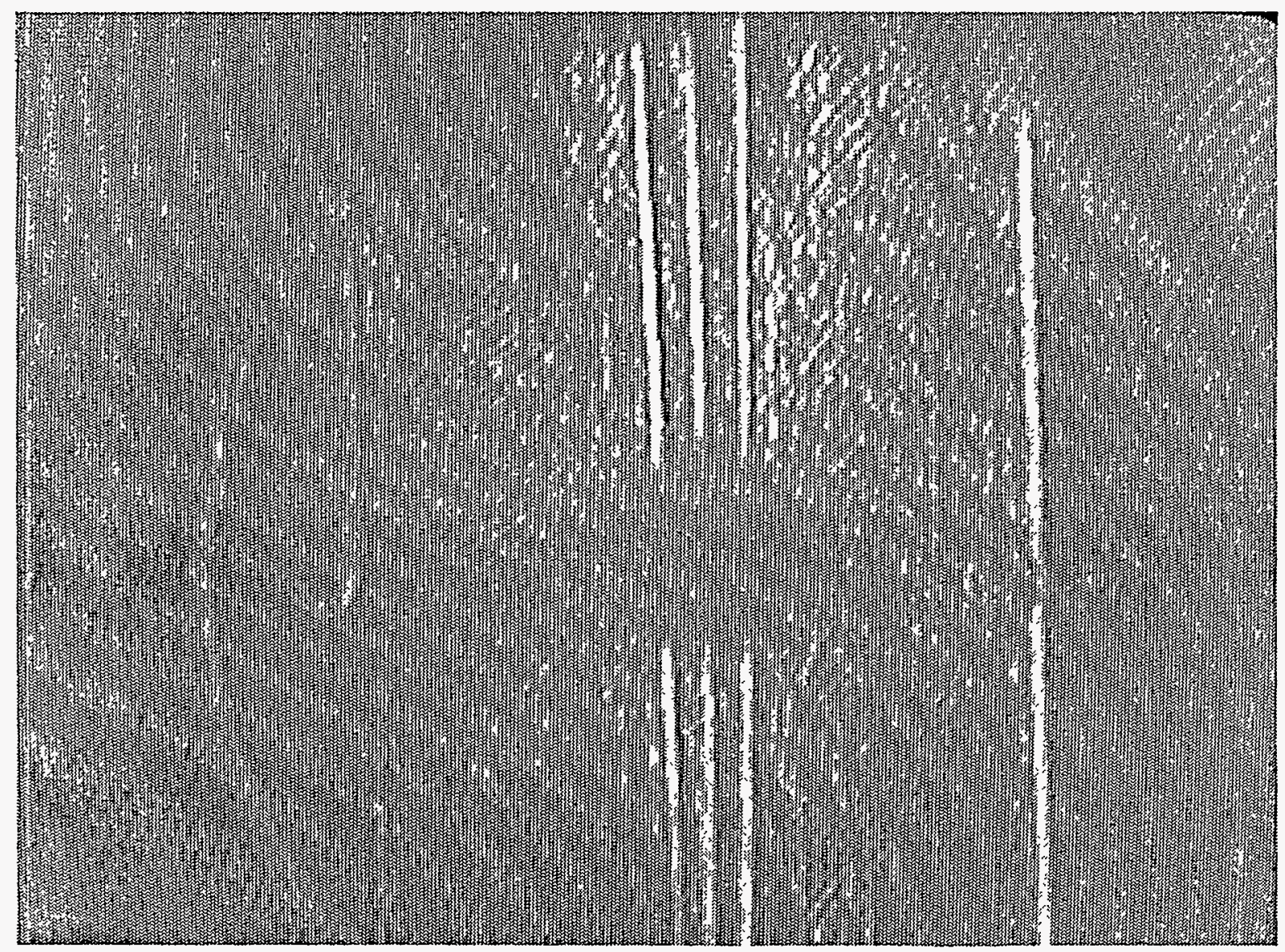

Photo \#14, Weld3, Filtered, Edge Detect, Vert Edge

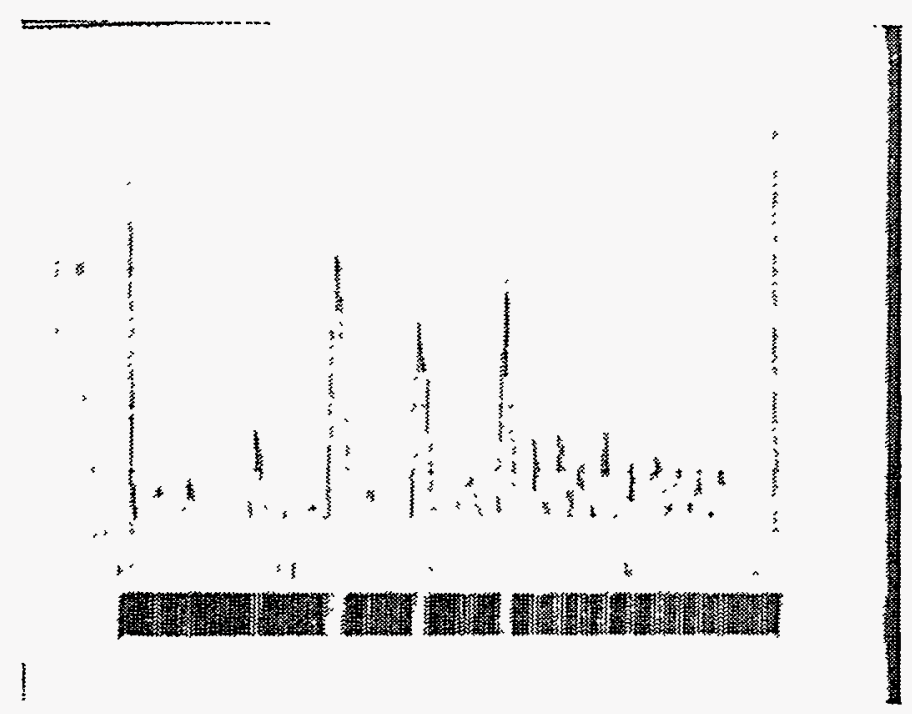

Photo \#15, Weld3, Filtered, Edge Detect, Vert Edge Line Profile 


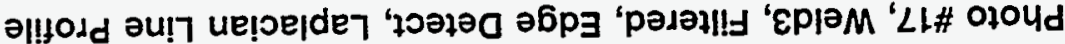

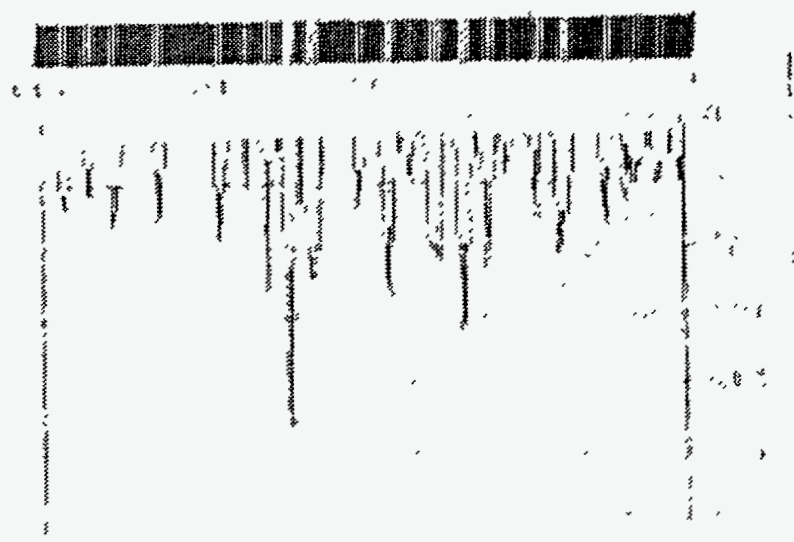

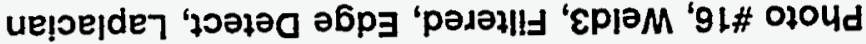

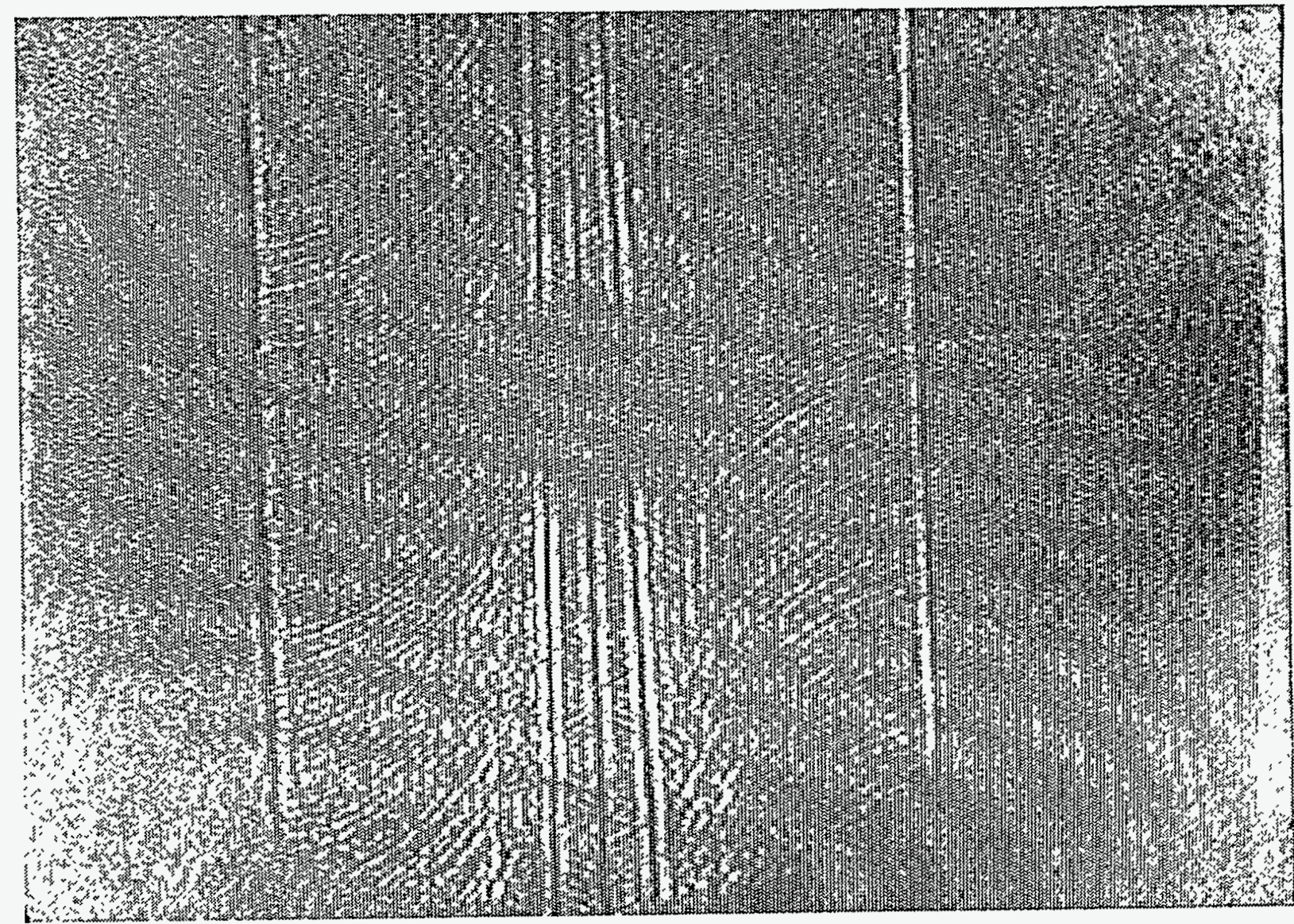




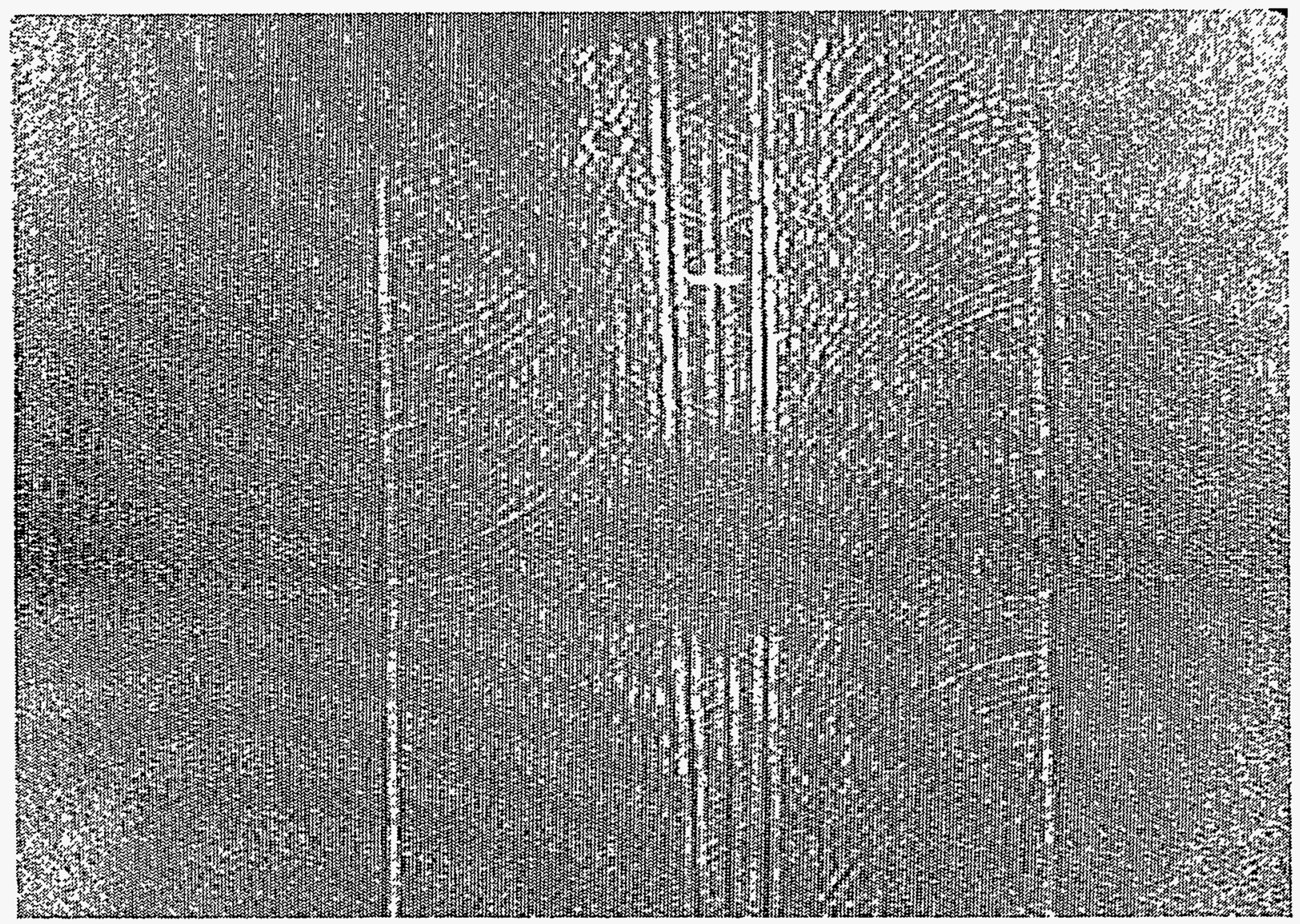

Photo \#18, Weld3, Filtered, Edge Detect, Laplacian (Frame Showing Line Prior to Line Profile)

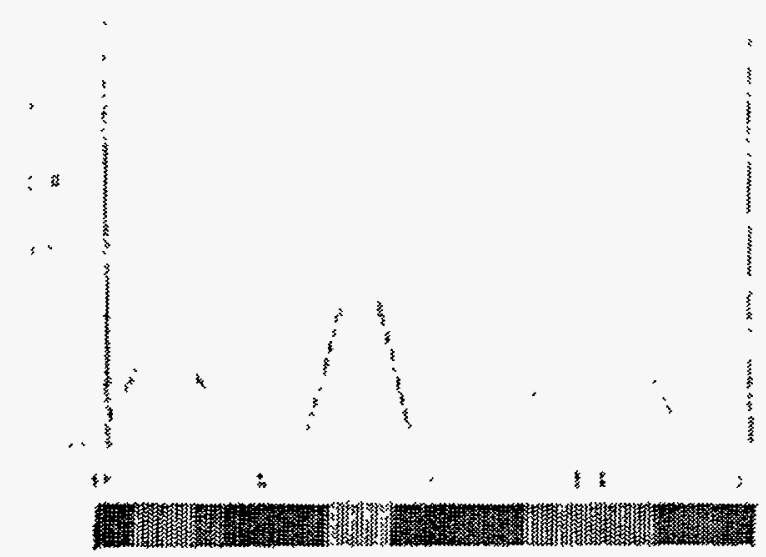

Photo \#19, Weld 3, Filtered, Edge Detect,

Laplacian Line Profile (Ref. No. 18) 


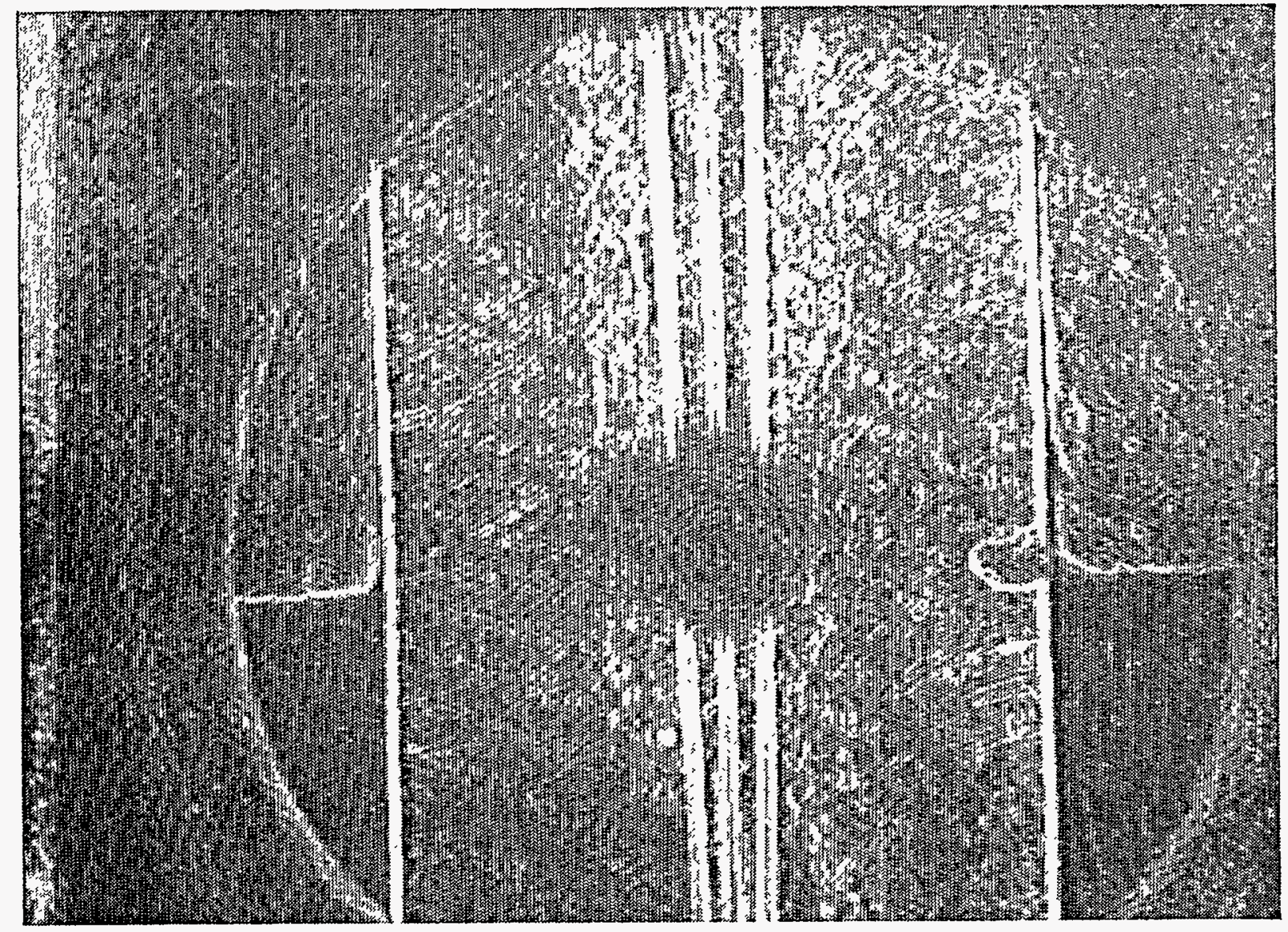

Photo \#20, Weld3, Filtered, Edge Detect, Sobel

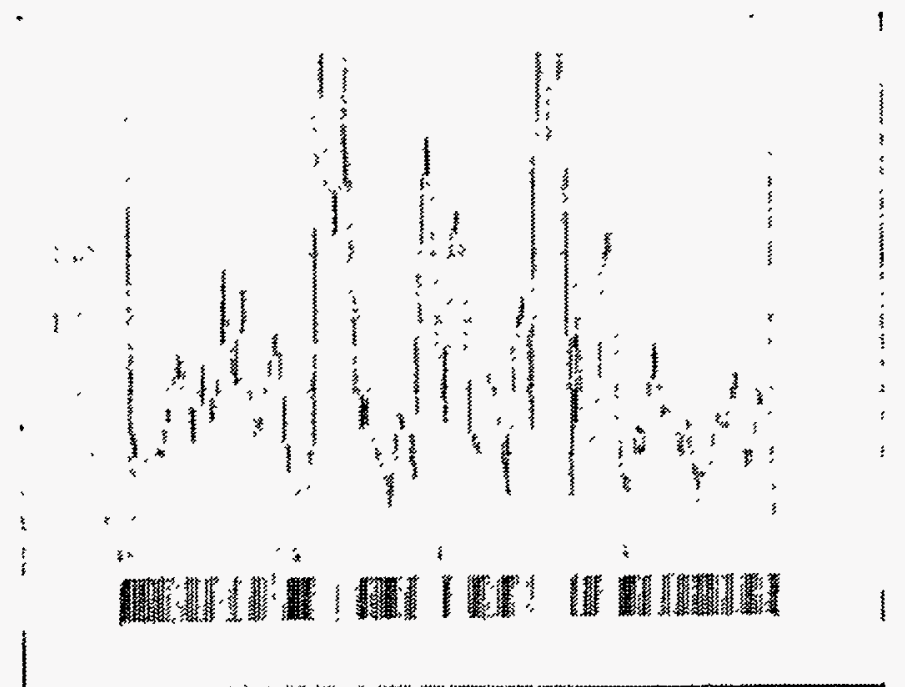

Photo \#21, Weld3, Filtered, Edge Detect, Sobel Line Profile 


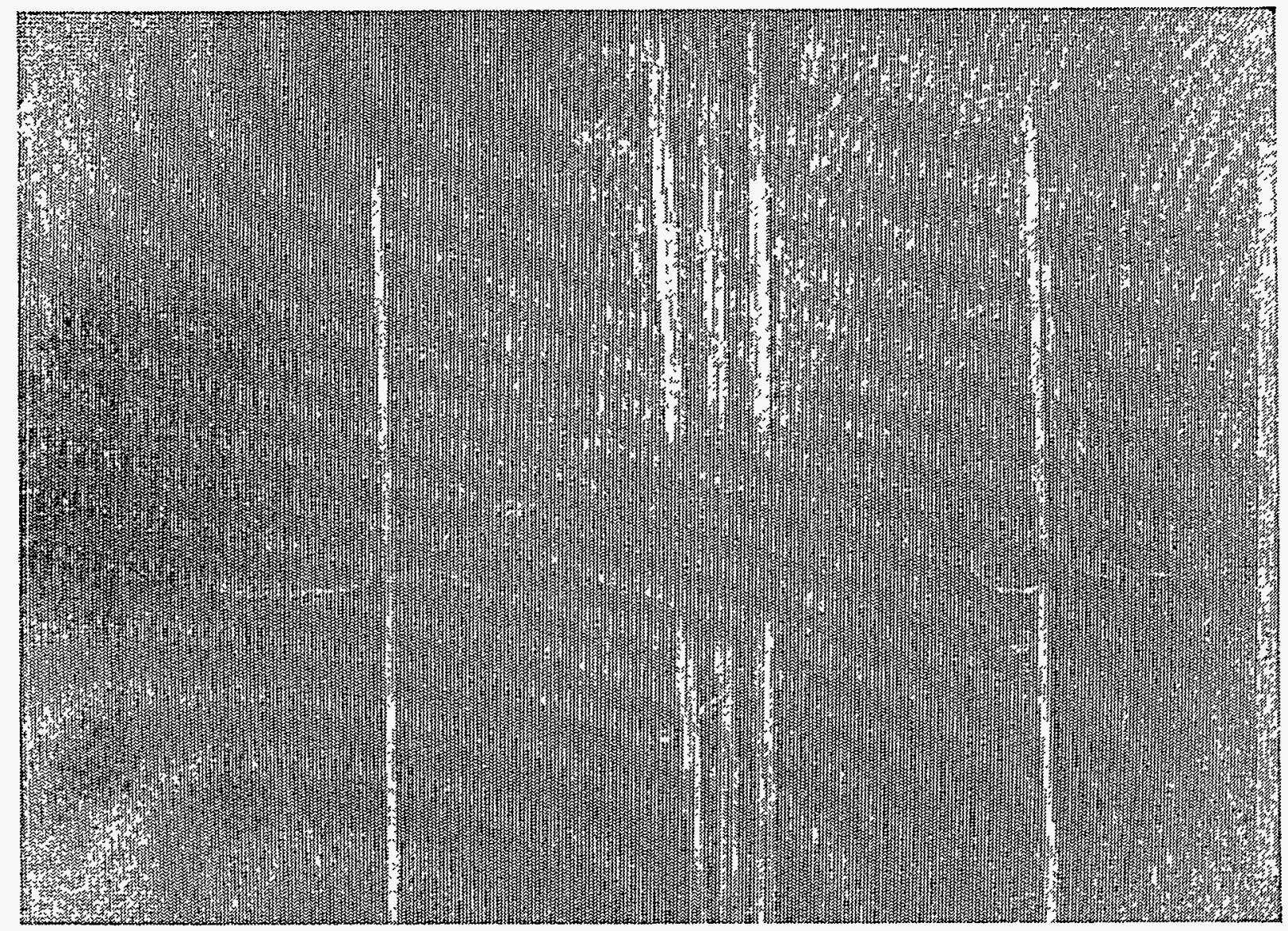

Photo \#22, Weld3, Filtered, Edge Detect, Roberts

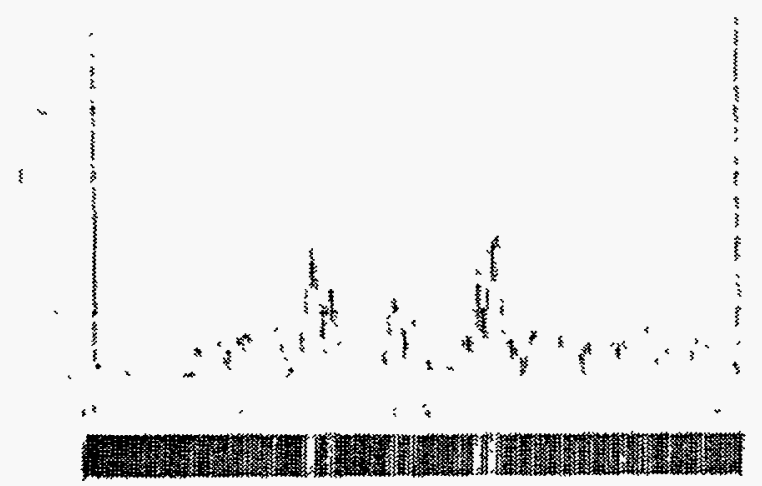

Photo \#23, Weld3, Filtered, Edge Detect, Roberts Line Profile 

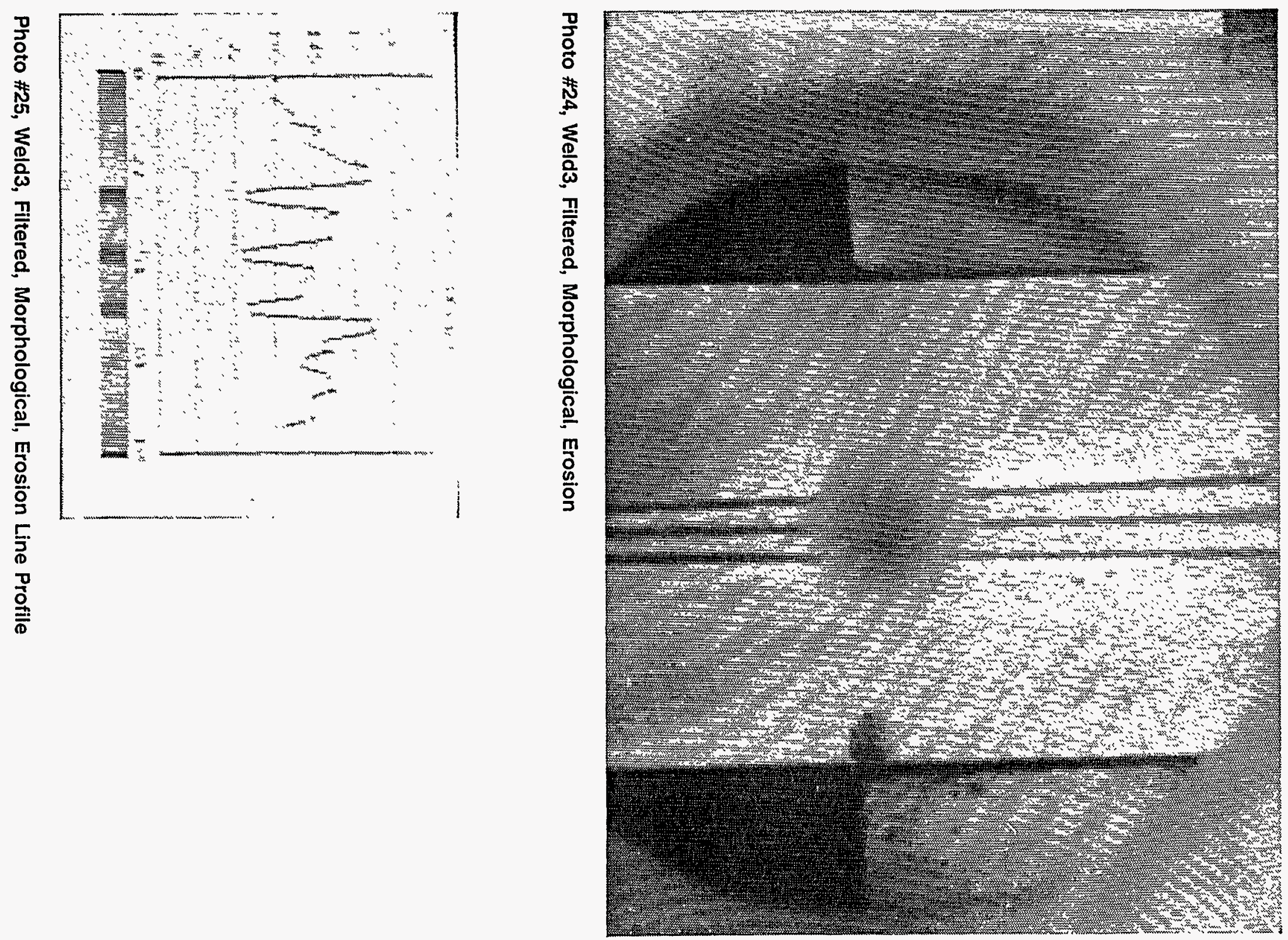


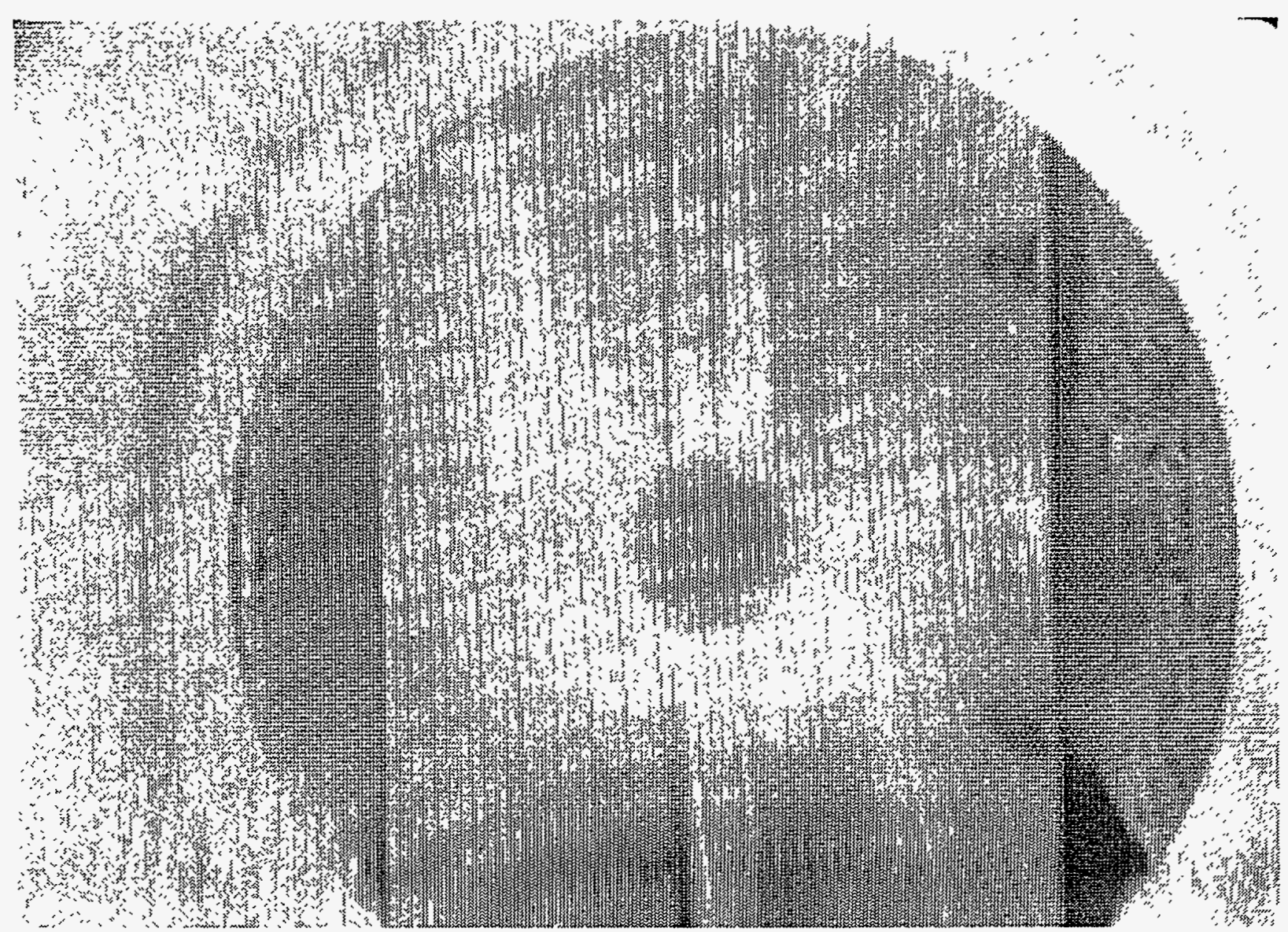

Photo \#28, Weld8, Raw Image

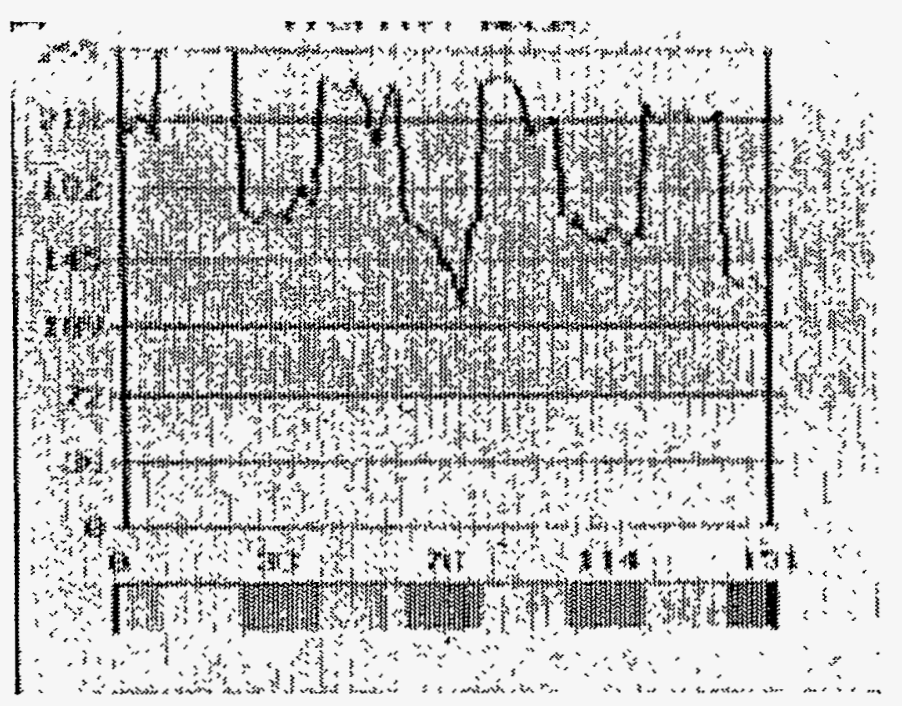

Photo \#29, Weld8, Raw Image Line Profile 


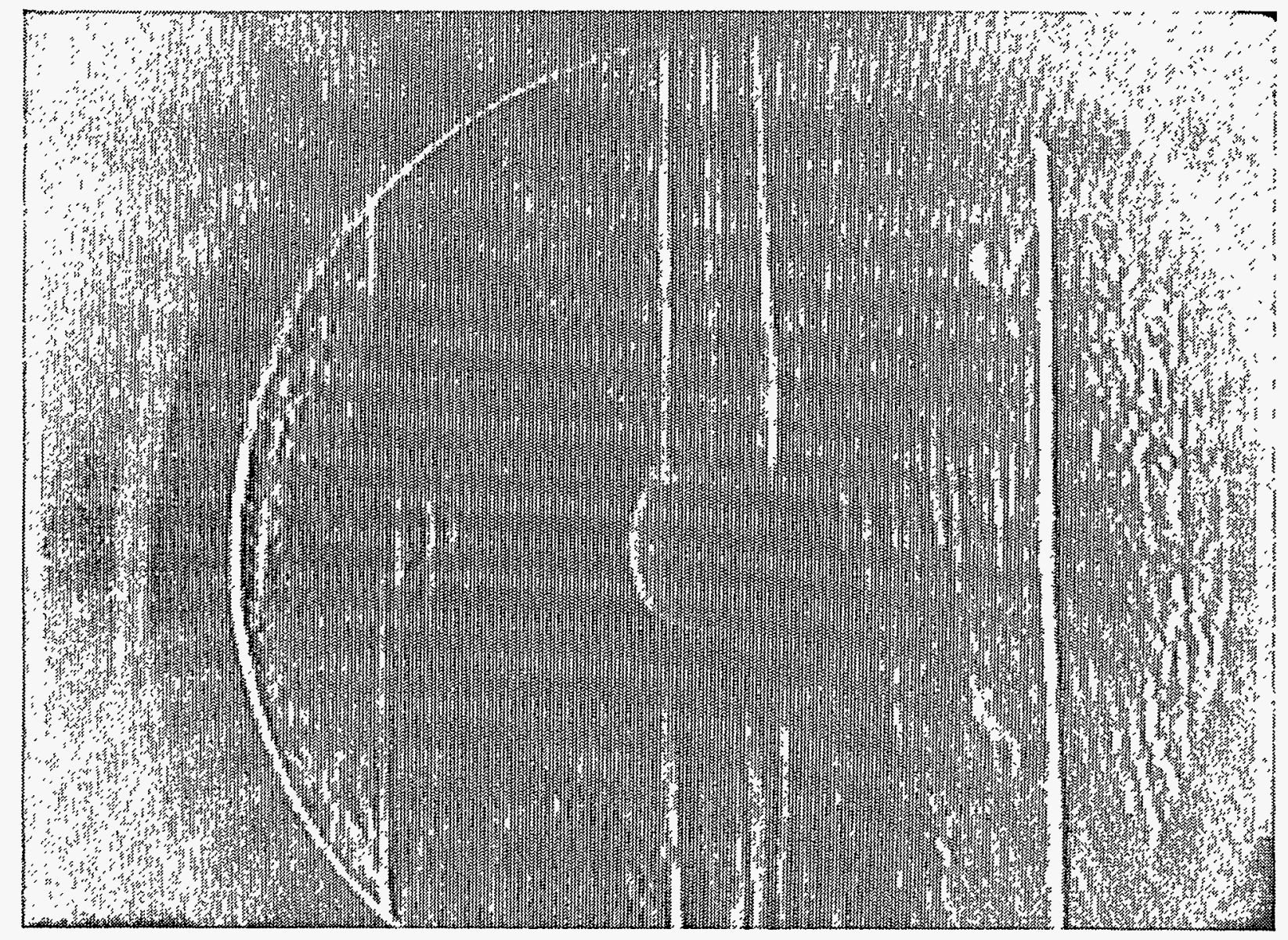

Photo \#31, Weld8, Filtered, Edge Detect, Vert Edge

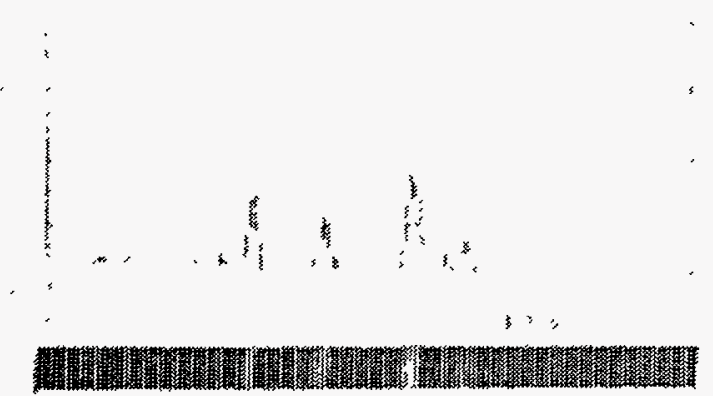

Photo \#32, Weld8, Filtered, Edge Detect, Vert Edge Line Profile 


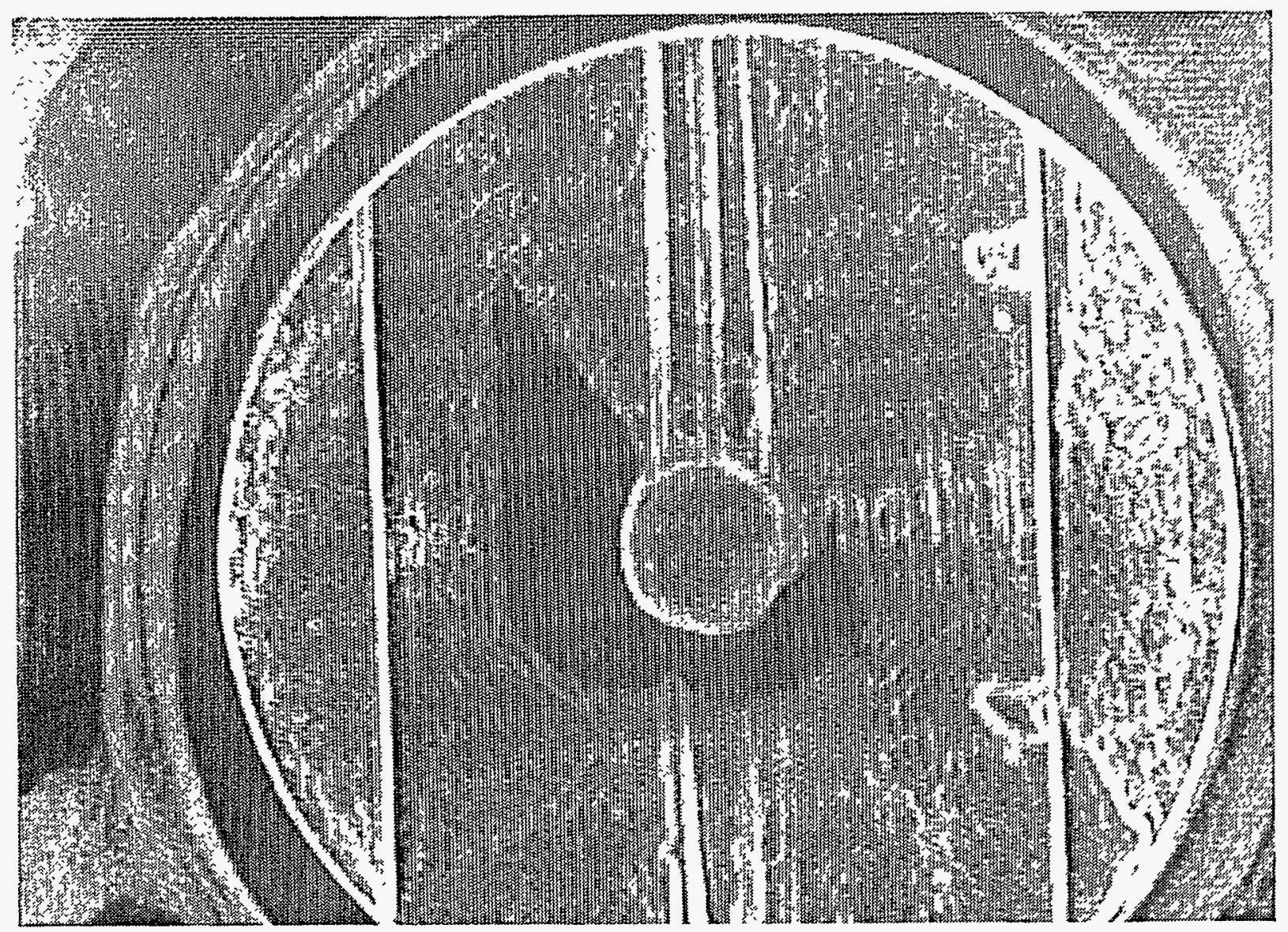

Photo \#34, Weld8, Filtered, Edge Detect, Sobel

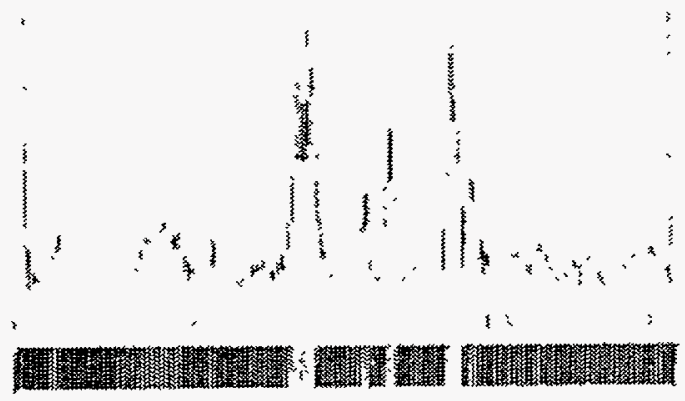

Photo \#35, Weld8, Filtered, Edge Detect, Sobel Line Profile 


\section{Appendix C}

\section{Pixel Intensity Data}




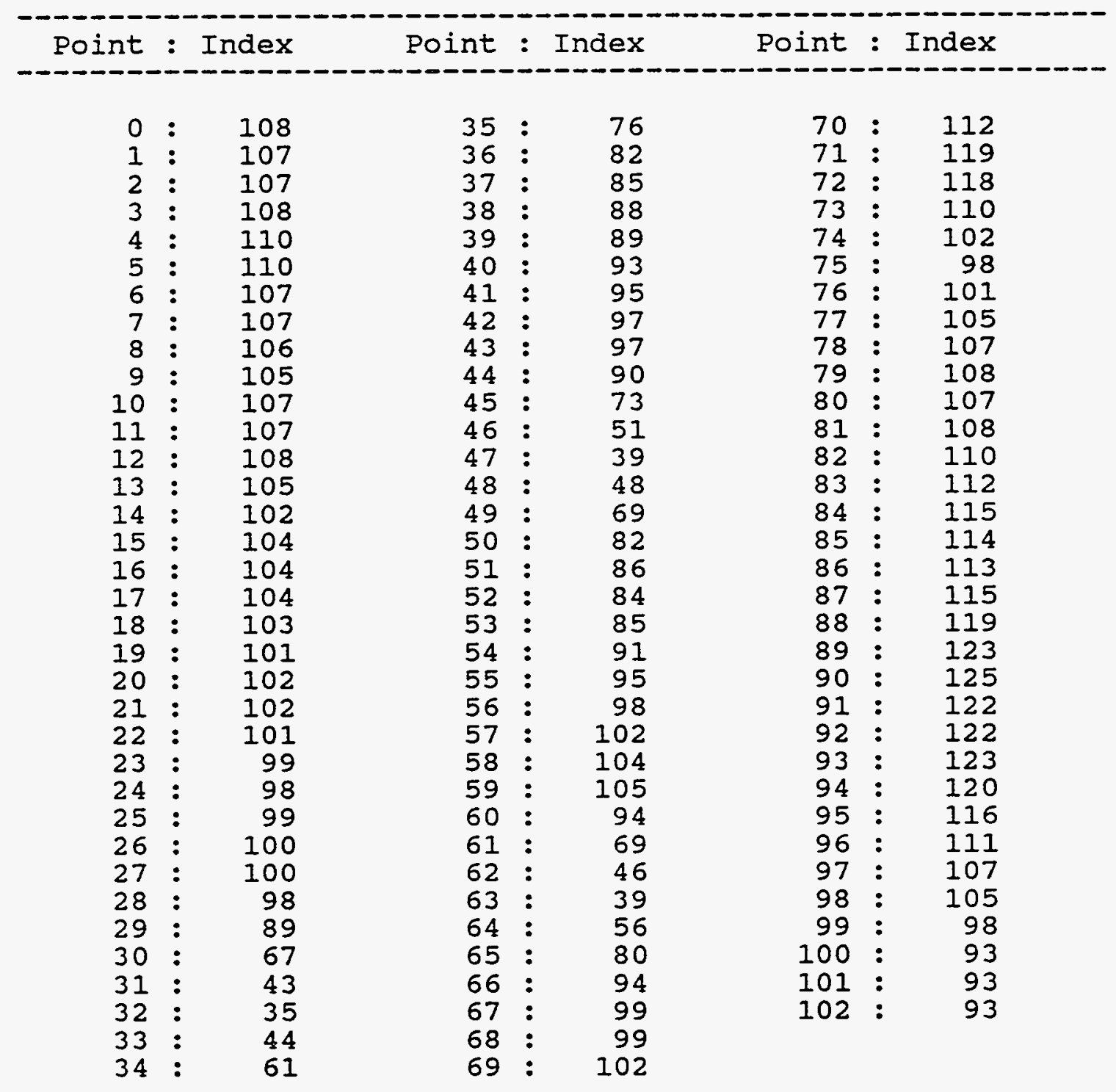

Line Profile

Minimum indexes indicate flange edges. 